\title{
ATRIBUTOS E INDICADORES DE DESEMPENHO LOGÍSTICO APLICADOS À GOVERNANÇA DE PLATAFORMAS LOGÍSTICAS
}

\section{ATTRIBUTES AND PERFORMANCE INDICATORS LOGISTICS APPLIED TO GOVERNANCE PLATFORMS LOGISTICS}

\author{
Rafael Mozart da Silva ${ }^{1}$; Eliana Terezinha Pereira Senna ${ }^{2}$ \\ ${ }^{1}$ Universidade Federal do Rio Grande do Sul - UFRGS - Porto Alegre - Brasil \\ rafmozart@terra.com.br \\ ${ }^{2}$ Universidade Estadual de Campinas - UNICAMP - Campinas - Brasil \\ lsennas@terra.com.br
}

\begin{abstract}
Resumo
O objetivo desta pesquisa foi elaborar uma matriz de indicadores de desempenho da gestão da cadeia de suprimentos e também uma matriz voltada aos indicadores relacionados ao serviço logístico que possam corroborar com a governança das plataformas logísticas, uma vez que estes empreendimentos mostram-se arranjos logísticos complexos onde são desenvolvidas diversas atividades com a participação de diferentes atores. A metodologia de pesquisa utilizada se classifica quanto ao nível como exploratória e a estratégia de pesquisa adotada foi a revisão bibliográfica. $O$ método de pesquisa utilizado foi o qualitativo. Como resultado desta pesquisa, identificou-se um conjunto de 19 dimensões de desempenho, composta por 114 indicadores de desempenho relacionados a cadeia de suprimentos e também ao serviço logístico que podem corroborar com a governança, a qual é composta por procedimentos associados à tomada de decisões, desempenho e controle das organizações. Os resultados do trabalho poderão ser utilizados para o desenvolvimento de novas observações e aplicações e que possam tornar ainda mais consistente o conhecimento que se tem acerca do desempenho da governança em plataformas logísticas.
\end{abstract}

Palavras-chave: desempenho logístico; governança; plataforma logística.

\section{Introdução}

A alteração nos padrões de competitividade tem conduzido à formação de diversos tipos de arranjos organizacionais entre empresas e entre grupos de empresas de todos os segmentos de atividade, os quais podem proporcionar economias de escala e escopo, bem como a aquisição de competências. O valor agregado por serviços logísticos mostra-se como sendo um dos principais fatores de competitividade dos terminais ou centros logísticos, pois isto ocorre em função das estruturas atingirem patamares de qualidade nos serviços de movimentação e de transporte e, a conectividade da infraestrutura capaz de atender as exigências de seus clientes (BOLUMOLE, 2003). 
A utilização de um sistema de operações logísticas que possa integrar as atividades e também os atores envolvidos na cadeia de abastecimento torna-se cada vez mais uma preocupação estratégica para as organizações. (CAMBRA-FIERRO e RUIZ-BENITEZ, 2009; TRAPPEY et al 2011; SILVA et al 2013). A fim de aproximar alguns dos objetivos da cadeia de suprimentos, que é a manutenção do nível de serviço e também os baixos custos globais ao longo da rede, existe a necessidade da criação de meios específicos de coordenação para gerenciar as intenções e interações entre os parceiros. As plataformas logísticas tem um importante papel de facilitação no fornecimento de um serviço complexo para a comunicação e avaliação das informações relevantes que possam impactar as operações dos canais de abastecimento (SILVA et al 2013; VÁNCZA et al 2010).

As plataformas logísticas (PL) podem possibilitar um melhor desempenho da rede logística, do nível de serviço e possibilitar ainda uma redução dos custos logísticos, porque este tipo de sistema logístico tem a capacidade de atender a clientes e produtos diferentes, oferecendo flexibilidade nas atividades de transporte, rapidez na movimentação de mercadorias e confiabilidade nos serviços prestados, tornando-se mais vantajosa para as organizações. Estas vantagens podem ser utilizadas pela região na qual a PL se insere, pois os impactos regionais referem-se às oportunidades de desenvolvimento local e ao aproveitamento do seu potencial (CAMPOLONGO et al 2010; GAJSEK et al, 2012; MEIDUTE், 2007; RIMIENĖ e GRUNDEY, 2007).

Neste contexto esta pesquisa teve como principal objetivo elaborar uma matriz de indicadores de desempenho da gestão da cadeia de suprimentos e também uma matriz voltada aos indicadores relacionados ao serviço logístico que possam corroborar com a governança das plataformas logísticas, uma vez que estes empreendimentos mostram-se arranjos logísticos complexos onde são desenvolvidas diversas atividades com a participação de diferentes atores. Para atingir o objetivo da presente pesquisa, foi adotada a estratégia de pesquisa baseada na revisão de literatura, onde se realizou consultas de forma sistematizadas em diversas bases de dados.

$\mathrm{Na}$ Seção 1 é apresentado o tema e uma breve contextualização do problema investigado. $\mathrm{Na}$ Seção 2, apresenta-se a metodologia e as etapas do método de trabalho utilizado para a realização desta pesquisa. O levantamento bibliográfico é apresentado na Seção 3. Na Seção 4, abordam-se os atributos e indicadores associados ao desempenho da cadeia de suprimentos e do serviço logístico. A análise e discussões dos resultados com a pesquisa são apresentados na Seção 5. Por fim, na Seção 6, demonstram-se as conclusões e contribuições do trabalho, as quais poderão ser utilizadas como hipóteses para novas pesquisas. 


\section{Metodologia de pesquisa}

Esta pesquisa ser caracteriza com relação a sua finalidade como uma pesquisa teórica, na medida em que objetiva gerar conhecimento para o esclarecimento de um problema específico, por meio de uma base bibliográfica. De acordo com Marconi e Lakatos (2009) a pesquisa bibliográfica é o levantamento da literatura já publicada, em forma de livros, revistas, publicações avulsas e imprensa escrita, pois a sua finalidade é fazer com que o pesquisador possa ter contato direto com o material escrito sobre um determinado assunto, auxiliando o cientista na análise de suas pesquisas ou na manipulação de suas informações.

Tendo em vista o objetivo mais específico desta pesquisa que foi elaborar uma matriz de indicadores de desempenho da gestão da cadeia de suprimentos e também de serviços logísticos que possam apoiar a governança das plataformas logísticas e considerando o volume de materiais publicados por diversos pesquisadores sobre a temática indicadores de desempenho ao longo do tempo, entende-se que esta pesquisa assume uma abordagem híbrida contendo uma revisão da literatura e também a análise de conteúdo das referências citadas nos trabalhos. De acordo com Karlsson (2009), a combinação de metodologias em pesquisas pode contribuir para enriquecer o estudo.

A base de dados utilizada para a pesquisa foram a; i) a ISI Web of Science, pois seu processo de busca possibilita o acesso a artigos que estão disponíveis em outras bases, como o Scopus, ProQuest e Wiley e que são publicados em periódicos indexados e também classificados com fator de impacto no Jornal Citation Reports (JCR). Os dados coletados sobre os trabalhos pesquisados, incluem resumos, referências citadas, quantidade de vezes que a publicação foi citada, os autores, a instituição, o periódico e o fator de impacto da revista dentre outros aspecto e ii) pesquisas na base de periódicos da Coordenação de Aperfeiçoamento de Pessoal de Nível Superior - CAPES utilizando a busca avançada por assunto através do acesso VPN (virtual private network), que consiste na criação de um túnel de comunicação criptografado entre o computador e o servidor VPN da instituição, provendo um acesso seguro à rede da Universidade Estadual de Campinas UNICAMP. As bases de dados consultadas foram: Academic Search Premier - ASP (EBSCO); Cambridge Journals Online; Oxford Journals (Oxford University Press); ScienceDirect (Elsevier); SpringerLink (MetaPress); Wiley Online Library; ACM Digital Library; ACS Journals Search; Emerald Fulltext (Emerald) OneFile (GALE) e IEEE Xplore.

No que tange aos seus objetivos, a pesquisa caracteriza-se como exploratória, pois têm-se como intuito conhecer a variável de estudo tal como se apresenta, seu significado e o contexto onde ela se insere. Para Collins e Hussey (2005) a pesquisa do tipo exploratória tem como objetivo 
encontrar padrões, ideias ou hipóteses e não testá-los ou confirmá-los e neste sentido utiliza-se um método mais aberto, e o foco está em reunir dados e impressões amplas sobre o fenômeno estudado.

O método utilizado nesta pesquisa foi o qualitativo. Segundo Creswell (2007) o objetivo de uma pesquisa qualitativa é compreender o contexto no qual determinado fenômeno se insere a partir da relação que tal fenômeno estabelece com o sujeito e por ele é interpretado. Ainda neste sentido Roesch (2006), estabelece que o método qualitativo procura o que é comum, mas permanece aberto para perceber a individualidade e os significados múltiplos, deixando de enfatizar uma necessidade de buscar uma média estatística. A fim de atingir os objetivos propostos para esta pesquisa, foi usado um método de trabalho, conforme a Figura 1:

Figura 1 - Método de trabalho utilizado na pesquisa

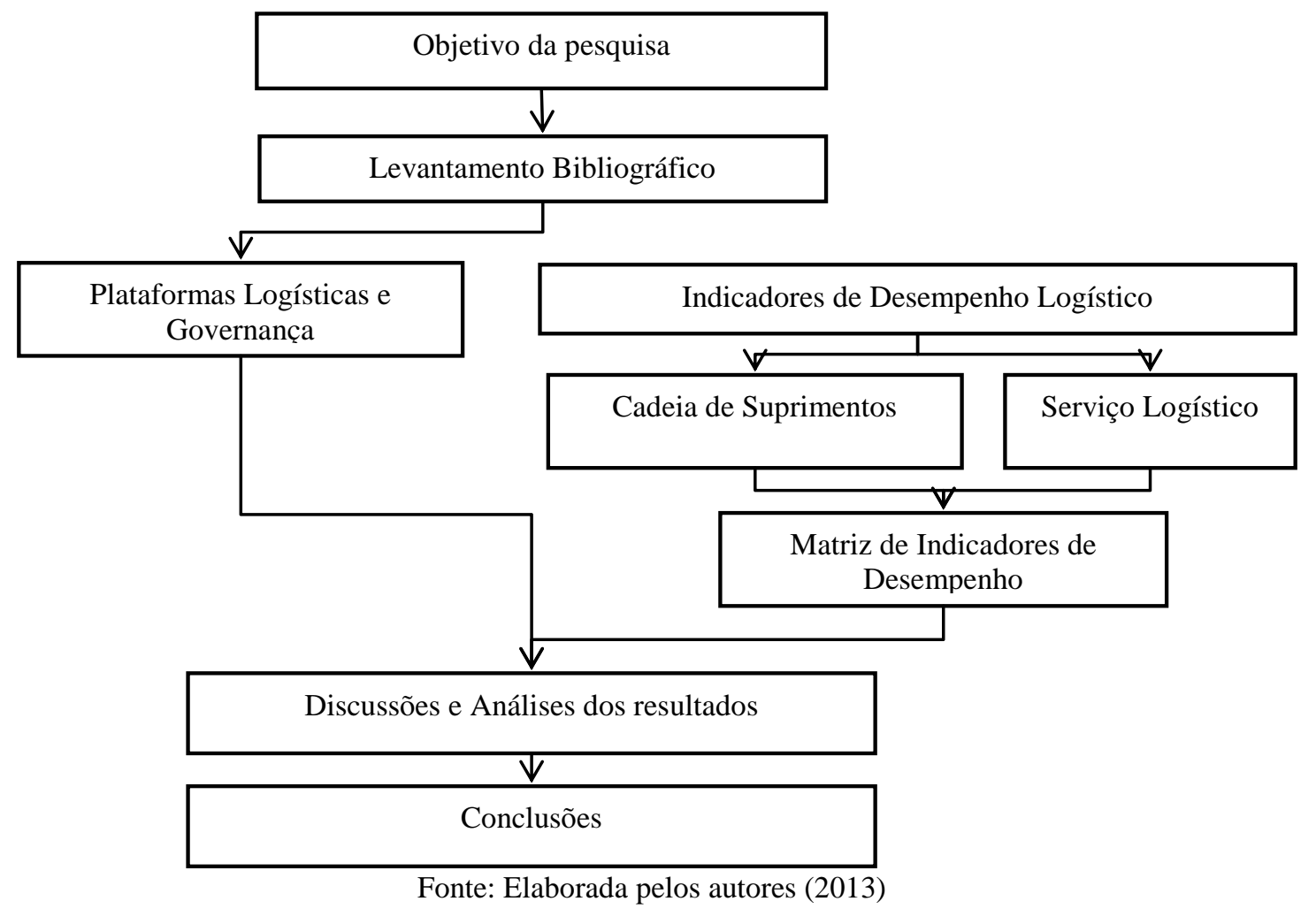

A estruturação das etapas da pesquisa permite aos pesquisados uma orientação clara e precisa de quais os passos deve ser seguidos na busca dos objetivos propostos por este trabalho. Outro ponto importante, é que a qualidade e confiabilidade das fontes de consulta dos materiais a serem pesquisados e analisados apresentam-se como uma variável importante e também relevante para a realização da revisão de literatura.

\section{Referencial teórico}

Nesta seção apresentam-se os conceitos e características relevantes para a compreensão sobre os aspectos relacionados às plataformas logísticas e a governança nestes ambientes e aspectos gerais e introdutórios sobre a logística e a cadeia de suprimentos. 


\subsection{Plataforma logística e a governança nestes ambientes}

A plataforma logística deve ser um ambiente flexível capaz de responder as estratégias dos canais do mercado. Neste ambiente são realizadas atividades logísticas (armazenagem, transbordo de cargas, cross-docking dentre outros) e os processos devem ser padronizados e medidos. A utilização de uma plataforma logística pode servir como uma fonte de vantagem competitiva, integrando atividades dentro de um cenário específico da cadeia de suprimentos sendo visto como um fator determinante e de sucesso para muitas empresas (ALDIN e STAHRE, 2003; DIAS et al, 2009; CAMPOLONGO et al, 2010).

Uma das características e pré-requisitos principais do conceito de uma plataforma logística esta relacionado aos seus objetivos, os quais devem ser estabelecidos pelos seus participantes. Uma plataforma logística inclui conceitos de operações integradas de logística no âmbito de estrutura física, processos e suas atividades, bem como os sistemas de informação necessários ao desenvolvimento das operações e geração de relatórios (ABRAHAMSSON et al, 2003; ALDIN e STAHRE, 2003; CAMPOLONGO et al, 2010; CAMBRA-FIERRO e RUIZ-BENITEZ, 2009; CRAINIC et al, 2004; DIAS et al, 2009; GAJSEK et al, 2012; MAZZARINO, 2012).

A gestão das plataformas logísticas pode ser privada, pública ou mesmo um misto entre as duas formas. Geralmente a gestão dos empreendimentos é centralizada, onde se tem a responsabilidade pelo planejamento das operações, o controle dos investimentos a serem realizados e também a administração e o suporte para o funcionamento local A governança deve incluir controles rígidos, sejam estes relacionados a qualidade, segurança, riscos, gestão ambiental dentre outros aspectos. Os investimentos realizados em plataformas logísticas são elevados e muitas vezes realizados sobre o conceito de uma parceria público-privada (PPP), sendo necessário o cumprimento de contratos e também uma adequada mensuração da performance do empreendimento. Um dos pontos críticos a serem considerados pela gestão nas plataformas relaciona-se aos objetivos singulares entre os atores envolvidos nos processos logísticos (BALLIS e MAVROTAS, 2007; HESSE e RODRIGUE, 2004; SILVA et al 2013; TSAMBOULAS e KAPROS, 2003; WAGNER, 2010).

As plataformas logísticas são ambientes complexos, os quais demandam a compreensão adequada das principais atividades realizadas, os atores envolvidos e principalmente os objetivos propostos com a utilização deste tipo de empreendimento logístico. As plataformas logísticas mostram-se como uma realidade em países desenvolvidos, tendo um papel ativo na logística das organizações e no âmbito público possibilitam uma reorganização dos espaços urbanos e também contribuem para uma melhor gestão e racionalização das questões ambientais, sociais, politicas e econômicas (SILVA et al, 2013). 
A governança é composta por procedimentos associados à tomada de decisões, desempenho e controle das organizações, com o fornecimento de estrutura para dar uma direção geral para a organização e para satisfazer expectativas razoáveis da prestação de contas para os que estão dentro ou são externos a própria organização (ALBERS, 2005; PECK et al, 2004). Outro ponto a destacar é que a governança, seja ela corporativa ou pública, envolve a relação entre diferentes atores e agentes, os quais estabelecem entre si um elo de interesses por diferentes razões, e em face disto, é necessário que se tenha uma governança adequada aos objetivos propostos entre as partes envolvidas. Uma plataforma logística pode ser instalada em diferentes ambientes (cidades, regiões etc...) e compreendem também a relação dos stakeholders, o que torna necessário a utilização de indicadores de desempenho para a mensuração da performance da governança e gestão destes empreendimentos logísticos.

Em uma plataforma logística são estabelecidos diferentes tipos de relações entre os atores envolvidos, as quais devem ser desenvolvidas de forma conjunta onde os objetivos necessitam estar alinhados para a obtenção de uma maior sinergia. Os benefícios sinérgicos decorrentes deste alinhamento, podem ser desde o compartilhamento e otimização de recursos até o desenvolvimento econômico dos empreendimentos que fazem parte das plataformas logísticas (HIGGINS e FERGUSON, 2011).

O modelo de governança pode ser considerado como um instrumento fundamental entre os diversos atores participantes de uma plataforma logística, onde o uso efetivo deste instrumento pode proporcionar uma maior eficiência na gestão dos recursos e também direcionar as competências específicas de cada um dos envolvidos de forma sinérgica (SILVA et al, 2013).

\subsection{Logística e gestão da cadeia de suprimentos}

De acordo com o Council of Supply Chain Management Professionals - CSCMP a logística é parte da cadeia de suprimentos, que planeja, implementa e controla de modo eficiente o fluxo direto e reverso e a armazenagem de bens, serviços e informações relativas entre o ponto de origem até o ponto de consumo de modo a atender os requisitos do cliente (CSCMP, 2012).

A cadeia de suprimentos pode ser compreendida como sendo uma rede de entidades de negócios autônomos ou semiautônomos responsáveis coletivamente pelas atividades de compras, produção e distribuição associadas com uma ou mais famílias de produtos. Neste sentido uma cadeia de suprimentos é uma rede de entidades que compram matérias-primas, transformam-nas em produtos intermediários e, então, em produtos finais, que são entregues aos consumidores por sistema de distribuição (LEE e BILLINGTON, 1995; SWAMINATHAN et al, 1996).

Para Dornier et al (1998), a gestão da cadeia de suprimentos apresenta dificuldades que podem ser provenientes da alocação de forma não coordenada e fragmentada de responsabilidades 
das diversas atividades da cadeia para diferentes áreas funcionais e entende-se como essência da gestão da cadeia a visão desta como integradora e coordenadora das atividades de produção e logística (KEARNEY, 1994; LAMBERT et al, 1998; POIRIER e REITER, 1996). Para Wood e Zuffo (1998), o supply chain management - SCM é uma forma de gestão desenvolvida com objetivo de sincronizar todas as atividades de produção, de modo a reduzir custos, minimizar ciclos e maximizar o valor agregado do produto para o cliente final transpondo barreiras entre departamentos e áreas.

A gestão da cadeia de suprimentos e a medição de desempenho inserida neste ambiente, os autores Lambert e Pohlen (2001) sugerem que as organizações que exercem a governança da cadeia identifiquem quais são os fornecedores e clientes considerados críticos, entre todos os existentes, para que possa ser estabelecido um adequado processo de gestão, caso contrário a governança e gestão poderia se tornar altamente complexa de se implantar. Os principais aspectos relacionados aos sistemas de medição e indicadores de desempenho relacionados ao serviço logístico e a cadeia de suprimentos foram pesquisados, analisados e são apresentados na próxima seção.

\section{Atributos e indicadores associados ao desempenho da cadeia de suprimentos e do serviço logístico}

A partir da síntese sobre os principais aspectos relacionados nas abordagens dos diversos autores sobre o sistema de medição e indicadores de desempenho apresentado na Seção 3.1 desta pesquisa, realizou-se uma classificação das obras analisas com relação a: i) abordagem no trabalho (Teórica-TO e Prática-PC), ii) o foco no que tange a aspectos financeiros e não financeiros, iii) Nível de medição (Estratégico -ET, Tático -TA, Operacional-OP) conforme a Tabela 1 e 3:

Tabela 1- Classificação das obras pesquisadas - cadeia de suprimentos

\begin{tabular}{cccccc}
\hline & Autor (s) & Ano & Abordagem & Foco & Nível \\
\hline 1 & Stewart & 1995 & PC & Financeira/ Não Financeira & ET/TA \\
2 & Beamon & 1999 & TO & Financeira/ Não Financeira & TA/OP \\
3 & Cravens et al & 2000 & TO & Financeira/ Não Financeira & ET \\
4 & Gunasekaran et al & 2001 & TO & Financeira/ Não Financeira & ET/TA/OP \\
5 & Lambert e Pohlen & 2001 & TO & Financeira/ Não Financeira & TA/OP \\
6 & Bowersox e Closs & 2001 & TO & Financeira/ Não Financeira & ET/TA \\
7 & Brewer e Speh & 2001 & PC & Financeira/ Não Financeira & TA \\
8 & Supply Chain Council & 2006 & PC & Financeira/ Não Financeira & ET/TA/OP \\
\hline \multicolumn{7}{l}{ Fonte: Elaborada pelos autores (2013) } & & &
\end{tabular}

Com relação aos sistemas de medição de desempenho da cadeia de suprimentos (Tabela 1), foram analisados as obras de Stewart (1995), Beamon (1999), Cravens, Piercy e Cravens (2000), Gunasekaran, Patel e Tirtiroglu (2001), Lambert e Pohen (2001), Bowersox e Closs (2001), Brewer e Speh (2001) e Supply Chain Council (2006), e relacionaram-se as dimensões, atributos e indicadores de desempenho propostos pelos autores. A dimensão pode ser compreendida como um 
campo e ou ambiente de referência e onde se define e sistematiza dos atributos de desempenho. Os atributos são elementos pertencentes a uma determinada dimensão e representam as características de um elemento ou de uma classe. Os indicadores estão relacionados ao que deve ser medido.

Considerando os dados descritos na Tabela 1, apresenta-se a abordagem dos autores sobre a mensuração do desempenho em cadeias de suprimentos:

1) Stewart (1995): Propõe uma estrutura de indicadores balanceados para melhorar o desempenho da cadeia de suprimentos e destaca cinco aspectos-chave para o êxito nas operações realizadas na cadeia de suprimentos, sendo estes: I) Desempenho da entrega, II) Flexibilidade, III) Responsabilidade; IV) Custo logístico e, V) Gerenciamento de ativos. Com relação aos indicadores econômicos da cadeia de suprimentos, o autor baseia-se nos dois últimos aspectos chave citados (custos logísticos e gerenciamento de ativos). Para o autor, em razão dos fatores como o alto custo de infraestrutura e compensação de flexibilidade através do uso de ativos se tornarem indícios de ineficiência da gestão da cadeia de suprimentos, tanto os custos totais logísticos como o gerenciamento de ativos devem ser priorizados no modelo de gestão da cadeia de suprimentos.

2) Beamon (1999): Para a autora um indicador de desempenho único para avaliar suas cadeias de suprimentos, não descreve adequadamente o desempenho do sistema. Propõe um modelo de avaliação de desempenho de cadeias de suprimentos que uma boa avaliação de desempenho da cadeia de suprimentos deve se basear em três dimensões, as quais estejam, necessariamente, relacionadas com um objetivo comum às organizações de uma mesma cadeia de suprimentos: Recursos (geralmente custos): as medidas relacionadas aos recursos incluem os níveis de inventário, as necessidade de pessoal, a utilização de equipamentos e custos e geralmente, procurase minimizar o emprego destes componentes. Tem-se como exemplo de indicadores de desempenho que podem ser utilizados para a análise dos recursos das cadeias de suprimentos: (a) Custo total: total dos custos dos recursos (fixos e variáveis); (b) Custos de distribuição: total dos custos de distribuição, incluindo transporte e manuseio; (c) Custos de manufatura: total dos custos de manufatura, incluindo processamento, manutenção e custos relacionados ao retrabalho; (d) Custos de inventário: custos associados à manutenção do estoque e, (e) Retorno sobre o Investimento (ROI): medida da lucratividade da organização. Outputs (normalmente responsabilidade pelos clientes): as métricas referentes às saídas incluem resposta aos consumidores, qualidade e o volume de produção. Muitos desses indicadores podem ser representados de maneira quantitativa, tais como: número de itens produzidos; tempo necessário para a produção de um determinado item e número de entregas on-time. Por outro lado, alguns indicadores, como satisfação do cliente e qualidade do produto, são difíceis de serem expressos de forma numérica. Estas medidas de desempenho devem, necessariamente, corresponder as metas da organização, bem como às 
necessidades dos clientes. Alguns exemplos de indicadores de desempenho das saídas da cadeia de suprimentos são: (a) Vendas: total de vendas, (b) Lucro: total de vendas menos as despesas, (c) Taxa de preenchimento: proporção de pedidos preenchidos imediatamente, (d) Taxa média de preenchimento de um item: taxa de preenchimento agregada dividida pelo número de itens, (e) Entregas on-time: mede o desempenho de entrega de um determinado item, pedido ou produto, (f) Atraso de produto: data da entrega menos data devida (due date), (g) Atraso médio dos pedidos: atraso agregado dividido pelo número de pedidos, (h) Antecipação média dos pedidos: antecipação agregada dividida pelo número de pedidos, (i) Porcentagem de entregas on-time: porcentagem das entregas realizadas na data prometida ou antecipadamente, (j) Probabilidade de falta em estoque: probabilidade instantânea de que não haja um item solicitado em estoque, (k) Número de pedidos devolvidos: número de pedidos devolvidos devido a falta em estoque, (l) Número de faltas no estoque: número de requisições de itens em falta no estoque, (m) Nível médio de devolução de pedidos: número de pedidos devolvidos dividido pelo número de itens, (n) Tempo de resposta ao consumidor: tempo entre a colocação de um pedido e sua a entrega correspondente, (o) Lead time da manufatura: tempo total necessário para a produção de um item ou lote em particular, (p) Erros de entrega: número de entregas erradas realizadas e, (q) Reclamação dos consumidores: número registrado de reclamações dos clientes (Bortoluzzi, 2010; Graham-Moore e Ross, 1993; Moori et al, 2007).

2.1. Flexibilidade (como o sistema reage à incerteza): a flexibilidade é um elemento essencial para o sucesso das cadeias de suprimentos. A flexibilidade deve ser entendida como sendo a capacidade que o sistema possui de reagir às instabilidades do ambiente. As seguintes habilidades podem caracterizar estruturas organizacionais flexíveis: (a) resposta às variações de demanda como sazonalidade; (b)resposta a baixos desempenhos da manufatura (quebra de equipamentos); (c) resposta a baixo desempenho de fornecedores; (d) resposta a baixo desempenho de entregas; e (e) resposta a novos mercados ou a novos competidores. As medidas de desempenho da cadeia de suprimentos devem estar alinhadas com os objetivos estratégicos da empresa e, ao mesmo tempo, considerar os efeitos das mudanças ambientais. A autora ressalta que o uso de recursos, o output e a flexibilidade são essenciais para o sucesso de uma cadeia de abastecimento e por essa razão, os sistemas de medida de desempenho devem incluir essas três categorias de medidas. $\mathrm{O}$ modelo proposto Beamon (1999) ressalta a importância de uma cadeia de suprimentos em obter de forma simultânea e com alto nível de eficiência de atendimento ao cliente, bem como a capacidade de resposta às mudanças do ambiente.

3) Cravens, Piercy e Cravens (2000): Desenvolveram um modelo para avaliação de desempenho de alianças estratégicas entre empresas tendo como base o Balanced Scorecard. O 
modelo proposto discute todo o processo de criação da parceria, desde a motivação para a sua implementação, até a definição dos indicadores de desempenho a serem utilizados. O impacto da qualidade do relacionamento pode ser mensurado através de fatores como confiança entre as pessoas, compromisso, cooperação, integração, informação compartilhada internamente, interações sociais, e a qualidade e quantidade de comunicações interorganizacionais. Esses indicadores podem aparecer em qualquer uma das perspectivas do Balanced Scorecard e podem ser mensurados por dois ângulos: o desempenho do projeto em si e o impacto do projeto sobre o desempenho da organização, tanto no curto como no longo prazo;

4) Gunasekaran, Patel e Tirtiroglu (2001): Os autores destacam que a mensuração tem como objetivo três níveis de desempenho: Estratégico, Tático e o Operacional. Neste sentido são definidos e classificados, conforme níveis acima, os principais aspectos da cadeia de suprimentos. Por fim são desdobrados seus subprocessos e definidos os indicadores a serem medidos, sendo esses financeiros e não financeiros. No sistema de medição propostos pelos autores, torna-se imprescindível estabelecer os processos chave da cadeia de suprimentos, ou seja, aqueles que requerem uma maior atenção e podem ser considerados os mais importantes. São seis os processos considerados críticos pelos autores:

I. Procedimentos para planejamento de ordens: envolvem o método de entrada de ordens considerando as especificações dos clientes que devem ser convertidas em informação útil e transferidas ao longo da cadeia; o lead time da ordem que compreende desde o recebimento da ordem do cliente até a entrega dos produtos e o trajeto da ordem do cliente que consiste no tempo gasto em diferentes rotas e atividades sem valor agregado;

II. Parcerias dentro da cadeia de suprimentos: Para avaliar as parcerias os autores sugerem os critérios como o: I) nível do compartilhamento de informação, II) iniciativas de economia de custos entre vendedor e comprador, III) extensão da cooperação mútua para melhoria da qualidade, IV) etapas na quais o parceiro é envolvido e, V) extensão da ajuda mútua nos esforços de resolução de problemas;

III. Nível de produção: o processo de produção necessita ser mensurado e tem grande impacto sobre aspectos da cadeia de suprimentos, podendo ser avaliados: I) linha de produtos na qual envolve a avaliação da linha de produtos em relação ao desempenho da cadeia, já que a estratégia da cadeia depende da variedade dos produtos e do grau de inovação, II) utilização da capacidade: impacta diretamente a velocidade de resposta à demanda do cliente, assim com a mensuração e controle da utilização da capacidade, se ganha em flexibilidade, lead-time e confiabilidade na distribuição e, III) efetividade das técnicas de programação: a programação determina a maneira pela qual os recursos são direcionados através de um sistema operacional, e 
sua efetividade tem um elevado impacto sobre o desempenho da cadeia de suprimentos, podendo melhorar seu desempenho. Os autores afirmam ainda que podem ser utilizados outros indicadores de desempenho, como: produtividade dos recursos humanos, comparação do tempo planejado para o processamento com relação ao realizado, níveis de inventário ao longo da cadeia e custos de produção;

IV. Canais de distribuição: A programação dos veículos e a localização do armazém têm um importante papel no desempenho da distribuição, da mesma forma que a entrega no prazo. A redução do lead time auxilia a melhorar o desempenho da distribuição, assim como a redução do percentual do estoque em trânsito, já que um alto percentual significa baixo giro do estoque, conduzindo um aumento desnecessário no capital comprometido. A apuração dos custos totais de distribuição também pode ser considerada importante, de modo a entender e avaliar os seus elementos, permitindo a identificação de trade-offs entre eles;

V. Serviços e satisfação do cliente: o atendimento da cadeia às especificações dos clientes deve ser mensurado a partir de indicadores de flexibilidade, tempo de resposta ao cliente e os serviços ao cliente após a transação, que representam valioso feedback para melhorias futuras na cadeia de suprimentos;

VI. Custos financeiros e logísticos da cadeia de suprimentos: A partir dos custos logísticos totais, pode ser avaliado o desempenho financeiro da cadeia de suprimentos e a partir do custeio das atividades logísticas, podem ser realizados trade-offs e avaliada a lucratividade dos clientes.

5) Lambert e Pohen (2001): Independentemente do grau de complexidade e superposição existente na maioria das cadeias de suprimentos, os gestores devem desenvolver indicadores para avaliar o desempenho de negócios chave através das empresas. Neste contexto, os autores desenvolveram um modelo que alinha o desempenho de cada ligação entre as mesmas. Este alinhamento é denominado de "alinhamento de desempenho dos processos-chave entre pares de empresas". A implantação do modelo inicia pela análise das interfaces entre processos focados na empresa em questão e move-se em direção a cadeia de suprimentos. O método de verificação fornece um alinhamento de desempenho entre pontos de origem e pontos de consumo com o objetivo geral de maximizar a percepção de valor da cadeia de suprimentos para cada membro da mesma. Os autores estabelecem sete passos para a implantação da sistemática que irá conduzir ao modelo de desempenho, sendo estes: i) mapeamento da SC do ponto de origem até o ponto de consumo identificando onde se posicionam as ligações chave; ii) utilizar os processos de gerenciamento das relações com clientes e o gerenciamento das relações com fornecedores para analisar cada ligação (processos chaves entre pares de empresas) e determinar onde valor adicional 
pode ser criado; iii) desenvolver uma demonstração de resultados para clientes e fornecedores com o objetivo de analisar o relacionamento de lucratividade entre as empresas; iv) realinhar processos e atividades para garantir o objetivo de desempenho; v) estabelecer indicadores de desempenho não financeiro que alinhem o comportamento individual com os objetivos dos processos da SC e metas financeiras; vi) comparar o valor interno com a capitalização de mercado das empresas com objetivos da cadeia de suprimentos e revisar os processos quando necessários e vii) replicar os passos para cada ligação na SC.

6) Bowersox e Closs (2001): Os autores afirmam que as medidas (indicadores) devem ser integradas, em razão de que "[...] a definição dada pelo fabricante ao serviço prestado ao cliente e sua perspectiva em relação a esse serviço podem ser bem diferentes das do atacadista”. Os autores utilizam-se de uma estrutura integrada para toda a cadeia de suprimentos, proposta pelo PRTM Consulting, que pode ser utilizada por várias empresas, composta por quatro tipos de indicadores, em que são monitorados resultados e diagnósticos. Os três principais objetivos do desenvolvimento e da implementação de sistemas de avaliação de desempenho, devem incluir o monitoramento, controle e o direcionamento das operações logísticas. O monitoramento das medidas acompanha o desempenho histórico do sistema logístico para que a gerência e os clientes sejam mantidos informados. Medidas de avaliação típicas incluem nível de serviço e os componentes dos custos logísticos. As medidas de controle acompanham continuamente o desempenho e são utilizadas para aprimorar um processo logístico, de modo a colocá-lo em conformidade quando excede padrões de controle. As medidas de direcionamento são projetadas para motivar o pessoal. Além do foco no desempenho interno e externo de uma organização, os autores alertam para a necessidade de medidas que possuam uma perspectiva integrada, compatível e consistente entre as funções da empresa e entre empresas do canal. Os autores indicam a necessidade do desenvolvimento de vários níveis de informação dentro da organização, cabendo a cada nível um perfil adequado de dados e informações (seletividade). Os quatro níveis aplicáveis à avaliação do desempenho logístico são: direcionamento (ao nível de gerentes), variação (ao nível de chefes de departamento), decisão (ao nível do vice-presidente) e política (ao nível do presidente ou do principal executivo). Um sistema de medida de desempenho deve considerar que as medidas podem ser efetuadas em atividades e em processos, bem como podem ser internas e externas. Em termos de logística, essas medidas podem ser classificadas nas seguintes categorias: Custos: Análise de custo total, custo unitário, custo como percentagem de vendas, frete de suprimentos, frete de entrega, custo de depósito, custos administrativos, processamento de pedidos, mão-de-obra direta, rentabilidade direta do produto, dentre outros. Serviço ao cliente: índice de disponibilidade de produtos, faltas de estoques, erros de expedição, entrega no prazo, pedidos pendentes, tempo de ciclo, feedback ao cliente, pesquisa junto ao cliente, dentre outras. Produtividade: unidades expedidas por funcionário, pedidos por 
representante de vendas, comparação com históricos, índice de produtividade, dentre outras. Gestão de ativos de logística: rotação de estoques, custos de manutenção de estoques, níveis de estoques, obsolescência de estoques, retorno do patrimônio líquido, retorno do investimento. Qualidade: índice de avarias, valor de avarias, número de solicitações de crédito, custo de mercadorias devolvidas e quantidades de mercadorias devolvidas;

7) Brewer e Speh (2001): utilizam o Balanced Scorecard para avaliar o desempenho em cadeias de suprimentos. A avaliação do desempenho em cadeias de suprimentos necessita de uma abordagem colaborativa e orientada pela confiança, de modo que as empresas percebam seu sucesso em termos do desempenho da cadeia inteira. Os autores reforçam da importância de serem adotados indicadores padronizados, ao longo da cadeia, os quais deverão ser desenvolvidos em um processo de colaboração. É necessário assegurar-se de que cada parceiro está gerenciando sua participação na cadeia, além das fronteiras de sua organização. Esse interesse pelo desempenho da cadeia deve ser apoiado pela alta direção e se não houver esse apoio, não devem ser investidos tempo e outros recursos no desenvolvimento do balanced scorecard. O inicio deste processo deve iniciar de forma gradativa, envolvendo um ou dois parceiros, para não incluir excessiva complexidade. Da mesma forma, o número de indicadores adotados deve ser o suficiente para facilitar o processo de adoção do balanced scorecard pelos parceiros.

8) Supply Chain Council (2006): Os processos de uma cadeia de suprimentos também foram discutidos pelo Supply Chain Council (SCC, 2006), que desenvolveu o Modelo de Referência para as Operações da Cadeia de Suprimentos (Supply Chain Operations Reference Model) ou SCOR. O SCOR define um modelo que pretende ser uma referência para a cadeia de suprimentos, permitindo que as empresas padronizem os termos e possam realizar benchmarking com seus parceiros. O SCOR define cinco processos da cadeia de suprimentos: i) Planejamento (plan), Aquisição (source), Fabricação (make), Entrega (deliver) e retorno (return). A sua fundamentação está em modelar as empresas em cinco processos-chave, a saber: planejamento, sourcing, produção, entrega e retorno. Cada um estes processos é decomposto em três níveis. Nos primeiros níveis é que são estabelecidos os indicadores-chave de desempenho, que orientam as ações de melhoria da organização. O modelo SCOR baseia-se por meio de uma estrutura para integração dos processos de negócios, métricas, melhores práticas e tecnologias dentro de uma estrutura unificada para apoiar a comunicação entre os parceiros da cadeia de suprimentos e para melhorar a gestão da eficácia da cadeia de suprimentos e também melhorar as atividades dessa cadeia.

Apresenta-se na Tabela 2 uma síntese dos indicadores de desempenho apontados pelos diversos autores. 
Tabela 2 - Matriz de indicadores de desempenho da cadeia de suprimentos

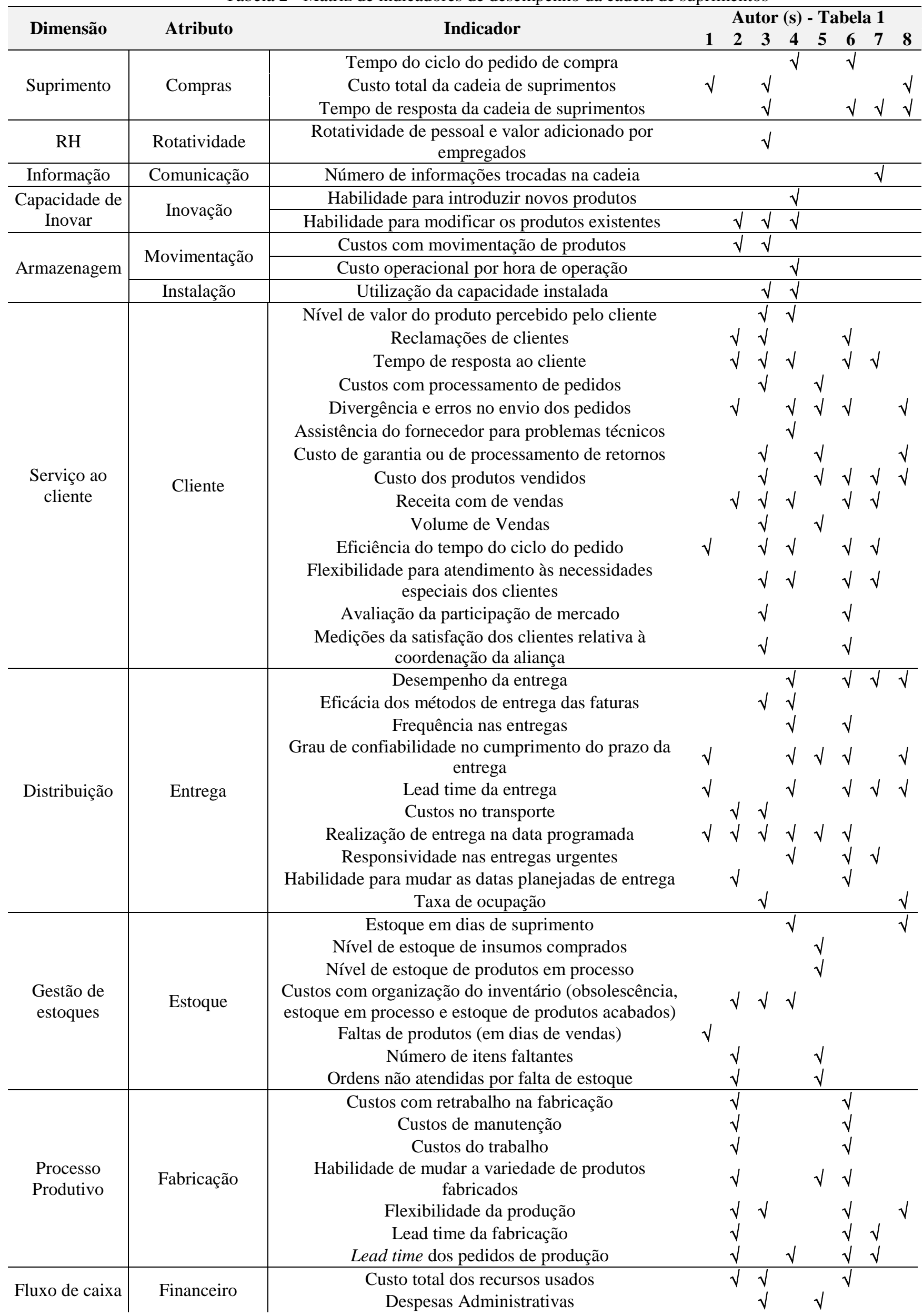




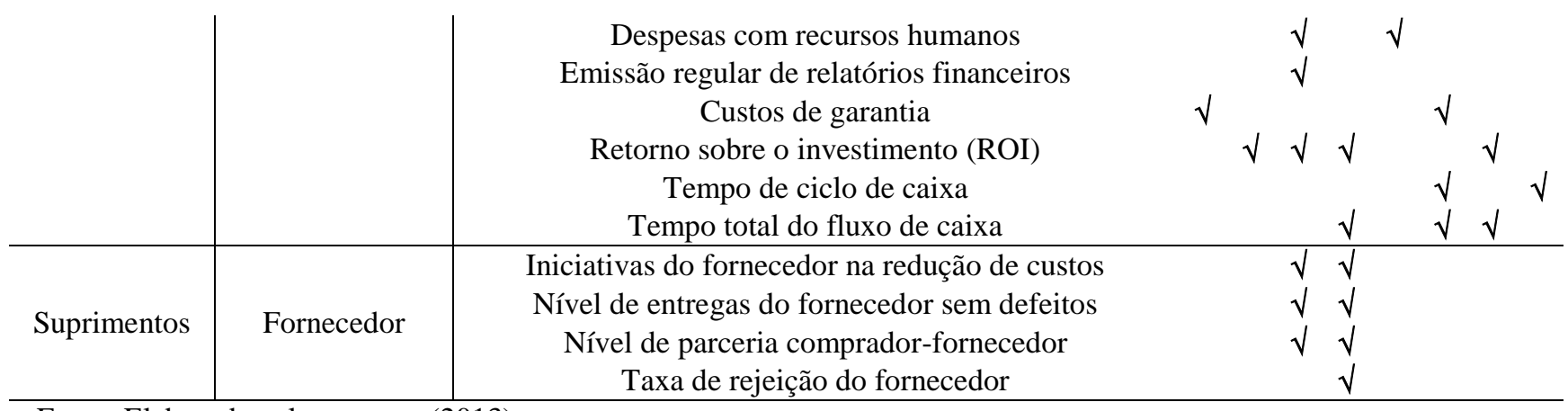

Fonte: Elaborada pelos autores (2013)

Identificou-se na revisão de literatura realizada, os principais aspectos relacionados ao serviço logístico. Foi realizada uma classificação das obras analisas com relação a: I) abordagem no trabalho (Teórica-TO e Prática-PC), II) o foco no que tange a aspectos financeiros e não financeiros, III) Nível de medição (Estratégico-ET, Tático-TA, Operacional-OP) conforme a Tabela 3:

Tabela 3 - Classificação das obras pesquisadas - serviço logístico

\begin{tabular}{cccccc}
\hline & Autor $(\mathbf{s})$ & Ano & Abordagem & Foco & Nível \\
\hline 1 & Chow et al & 1994 & TO & Não Financeira & TA/OP \\
2 & Chistopher & 1997 & TO & Financeira/ Não Financeira & ET/TA \\
3 & Dornier et al & 1998 & PC & Financeira/ Não Financeira & ET/TA \\
4 & Rey & 1999 & TO & Financeira/ Não Financeira & ET/TA \\
5 & Bowersox e Closs & 2001 & TO/PC & Financeira/ Não Financeira & ET/TA/OP \\
6 & Hijjar et al & 2005 & PC & Financeira/ Não Financeira & ET/TA \\
7 & Ballou & 2006 & TO/PC & Financeira/ Não Financeira & ET/TA/OP \\
\hline
\end{tabular}

Fonte: Elaborada pelos autores (2013)

Os principais aspectos relacionados aos sistemas de medição de desempenho dos serviços logísticos, extraídos da revisão bibliográfica baseada nos trabalhos de Chow et al, (1994), Christopher (1997), Dornier et al, (1998), Rey (1999), Bowersox e Closs (2001), Hijjar et al, (2001) e Ballou (2006) são descritos abaixo:

1) Chow et al (1994): realizaram um estudo através de uma revisão bibliográfica para analisar a definição e mensuração de desempenho na logística, bem como, identificar métodos de coletas de dados, fontes e medidas utilizadas. O estudo envolveu artigos publicados em cinco periódicos mundiais sobre logística entre o período de 1982 e 1992 e os autores concluíram que desempenho logístico pode ser considerado um subitem de uma noção mais ampla de desempenho organizacional ou da firma. O desempenho é multidimensional e deve-se encontrar um grupo de mensurações que possam captar um conjunto máximo de dimensões importantes nos horizontes de curto e longo prazo. O desempenho logístico pode ser definido como a extensão até onde objetivos são atingidos.

2) Christopher (1997): aborda a avaliação do desempenho logístico sob duas perspectivas: em termos absolutos que esta baseada em custos e em termos relativos que baseia-se na comparação 
com a concorrência (benchmarking). Sendo o enfoque dos custos voltado para o custeio logístico e análise de custos e receitas. Trabalha-se com a ideia de missão, ou seja, um conjunto de metas do serviço ao cliente que devem ser alcançadas através do sistema. Quanto ao enfoque do benchmarking o autor acredita que se deve fazer a medição interna e comparar com as melhores práticas do mercado em que atua. Trata-se de uma abordagem com forte enfoque nos custos assim como no serviço ao cliente. O serviço ao cliente pode ser compreendido como a oferta consistente de utilidade de tempo e lugar, tendo como função de elevar o valor de uso, implicando que o produto passe a ganhar mais valor sob o ponto de vista do cliente na medida em que o serviço adicionou valor ao produto em si, ou seja, o produto em si mais o pacote de serviço ofertado. Durante as suas pesquisas o autor identificou três aspectos sob os quais o serviço ao cliente poderia ser examinado: elementos da pré-transação, transação e pós-transação. Os elementos da prétransação estão relacionados às políticas ou aos programas corporativos. Os elementos de transação são as variáveis diretamente envolvidas no desempenho da função de distribuição física. E os elementos da pós-transação geralmente estão relacionados ao suporte ao produto em uso. Para o autor caso seja necessário controlar o desempenho do serviço ao cliente, esse controle deve estar relacionado aos padrões pré-determinados. Para que os padrões possam ser eficazes, os mesmos devem ser definidos pelos clientes;

3) Dornier et al (1998): Os autores propõem a mensuração do desempenho logístico tendo por base dois cenários globais: integração funcional e integração setorial e também reforçam a importância do planejamento e do controle como forma de gestão. O planejamento através de informações quantitativas e qualitativas sobre qualidade, pontualidade e produtividade. O controle está baseado no monitoramento dos custos de aquisição, produção e distribuição assim como o preço de venda dos produtos prontos. Na definição e desenho de um sistema de medição de desempenho devem ser considerados os seguintes tópicos:

a) Objetivos das medidas: Medição do desempenho da atividade (volume) e da logística; Definição dos objetivos e comparação da situação real em todos os momentos; Acompanhamento de um plano de mercado (análise de lacunas relativas aos objetivos); Determinação das alavancas que ajudarão a atingir os objetivos e identificar as ações prioritárias a serem implementadas e, Liderança, mobilização e gerenciamento de pessoal;

b) Princípios de projeto de medidas: os três principais critérios para medidas eficientes são a velocidade, confiabilidade e simplicidade, e os princípios básicos incluem: Organização dos indicadores por prioridade; Segmentação de medidas; Visualização do conteúdo da função; Classificação dos objetivos da função ou equipe; Seleção de indicadores que lidam com qualidade e, Formatação eficaz das medidas; 
c) Características de medidas eficazes: As medidas devem ter como objetivo a capacidade de atuação sobre as causas e devem incluir: Independência: cada indicador mensurando determinado aspecto da atividade logística; Conexão com outros indicadores: cada indicador adicionando informações ao quadro fornecido pelos outros; Adequação: os indicadores devem ser representativos dos fenômenos que se propõem a medir; Objetividade: indicadores úteis não julgam, mas definem quantitativamente a extensão e direção do problema; Regularidade: quando o mesmo controle é aplicado exatamente nas mesmas condições, o resultado observado é estritamente o mesmo; Coerência: a definição de um indicador não deve variar. Deve ser sempre a mesma: no espaço e no tempo; Simplicidade: os melhores indicadores permitem que as medidas- chaves sejam compreendidas imediatamente e, Cumulativo: essa característica permite cumulação sucessiva de dados.

4) Rey (1999): Estrutura o processo de avaliação do desempenho logístico com base em quatro pontos principais: I) por que medir o desempenho logístico, II) como medir o desempenho da função logística, III) que indicadores utilizar e, IV) benchmarking de indicadores de desempenho de logística. As relações entre a política de serviço ao cliente, a política de estoques, materiais, transporte e distribuição e as políticas de armazenagem são intrínsecas ao desempenho que necessitam ser explicitadas através dos indicadores de desempenho adequados. Uma alternativa para implementar e justificar uma estratégia ou diferentes iniciativas em logística é elaborar um conjunto de indicadores que demonstrem de forma quantitativa o impacto das iniciativas na melhoria dos indicadores em âmbito global. Ao abordar como medir o desempenho logístico, a autora menciona a necessidade de haver uma inter-relação entre os indicadores de desempenho logístico e os indicadores de desempenho corporativo e neste sentido pode se utilizar a abordagem de Kaplan e Norton (1997). Os indicadores têm sido construídos com base em elementos que contribuem para melhorar a posição competitiva da organização. De modo geral, as empresas competem com base em quatro elementos: i) custo: habilidade de proporcionar bens e serviços ao menor custo possível; ii) produtividade: habilidade de produzir os maiores resultados possíveis com uma utilização menor da quantidade de recursos disponíveis; iii) qualidade: habilidade de gerar bens e serviços que satisfaçam ou excedam as expectativas dos consumidores e, iv) tempo: capacidade da empresa de responder às mudanças no menor tempo possível.

Os quatro grupos de indicadores podem ser considerados complementares e devem ser avaliados de maneira simultânea e complementar. A avaliação de desempenho logístico mostra-se fundamental para o sucesso das empresas neste atual ambiente mercadológico, caracterizado como altamente competitivo. A avaliação contribui para a definição correta dos custos, bem como das estratégias corporativas. 
5) Bowersox e Closs (2001): Para os autores é imprescindível entender por completo as necessidades dos clientes, as quais precisam ser atendidas para o estabelecimento da estratégia logística. O serviço ao cliente ocorre através do marketing centrado no cliente, pois o serviço ao cliente representa o papel da logística no cumprimento do conceito de marketing. Neste sentido, os autores propõe que um programa de serviço ao cliente necessita identificar e priorizar todas as atividades exigidas para satisfazer às exigências logísticas dos clientes, melhor que os concorrentes, identificando padrões claros de desempenho para cada uma das atividades e medidas relativas a esses padrões. Os atributos de disponibilidade, desempenho operacional e confiabilidade do serviço, são fundamentais no serviço básico ao cliente, assim como para o atendimento do pedido perfeito. O serviço ao cliente pode ser dividido em serviço básico e serviço de valor agregado. O serviço básico é composto por esses três atributos, considerados da seguinte forma: i) Disponibilidade: refere-se a disponibilidade do estoque quando o produto é desejado pelo cliente, sendo medida pela frequência ou número de vezes ou dias em que um determinado produto controlado chega ao saldo zero, pedidos entregues por completo e percentual entregue do total encomendado, ii) Desempenho operacional: esta relacionado com a entrega pontual, ou seja, consistência do tempo de ciclo e flexibilidade operacional, iii) Confiabilidade: cumprimento do nível de serviço combinado. Os serviços de valor agregado são desenvolvidos para clientes específicos, adequando-se a cada caso. Para os autores a condição básica para se alcançar a qualidade em logística é a realização de uma avaliação constante, manter a disponibilidade de estoque e o desempenho operacional, os quais são considerados essenciais aos clientes.

6) Hijjar et al (2005): Os níveis de serviço são o foco do planejamento logístico e por tal motivo devem ser monitorados e conhecidos, pois serão importantes indicadores de desempenho do processo logístico. Os indicadores de desempenho interno são imprescindíveis para o gerenciamento e controle das atividades logísticas, porém estes indicadores devem estar relacionados com os indicadores externos, os quais são medidos através da percepção do cliente. A partir da perspectiva do cliente pode ser obter informações sobre os reais níveis de satisfação e minimizar as lacunas de percepção entre a empresa e o cliente. Faz-se necessário conhecer não somente a percepção dos clientes e a importância de cada item ou serviço, mas também o grau de satisfação em relação ao desempenho da empresa. A visão do cliente é um indicativo de mercado e a empresa deve apresentar soluções aos pontos de melhoria evidenciados, não se restringindo a atender de forma imediata as solicitações e também apresentar soluções que possam alcançar as metas de nível de serviço previamente definidas. Os indicadores de desempenho internos devem coexistir com os indicadores externos, medidos a partir de percepções de fora da empresa, ou seja, as percepções dos clientes. A qualidade do serviço oferecido ao cliente é importante, na medida em que as expectativas podem com relação aos serviços podem variar de um cliente para o outro. Neste 
contexto a segmentação de mercado surge como forma de aumentar a efetividade dos serviços oferecidos, onde os recursos são direcionados de forma adequada, sugerindo a segmentação de serviços a partir das expectativas dos clientes;

7) Ballou (2006): Define serviço ao cliente como a cadeia de atividades de satisfação das vendas, a qual, usualmente, começa com a entrada do pedido e termina com a entrega do produto ao cliente; em alguns casos, continuando com serviços de manutenção de equipamento ou outro suporte técnico, pois o serviço ao cliente pode ser considerado um termo amplo que pode incluir muitos elementos, compreendendo desde a disponibilidade do produto à manutenção pós-venda. Para o autor o sistema de desempenho pressupõe um controle efetivo sobre o processo no qual o desempenho planejado é alinhado, ou mantido em acordo, com os objetivos desejados pela organização, ou seja, o processo de controle é aquele no qual se deve comparar o desempenho real ao desempenho planejado e de iniciar ações corretivas para aproximar os dois, se necessário. $\mathrm{O}$ serviço ao cliente possui elementos definidos como:

I. pré-transação: são os responsáveis pela criação de um ambiente favorável à realização da transação;

II. transação: ocorrem durante a realização da venda e estão relacionados diretamente à entrega dos produtos aos clientes e;

III. pós-transação: se referem ao acompanhamento do produto após a transferência ao cliente, ou seja, ao fornecimento de suporte durante o ciclo de vida do produto.

$\mathrm{Na}$ Tabela 4 apresenta-se os indicadores de desempenho associados ao serviço logístico que foram abordados pelos autores anteriormente:

Tabela 4 - Matriz de indicadores de desempenho do serviço logístico

\begin{tabular}{|c|c|c|c|c|c|c|c|}
\hline \multirow{2}{*}{ Dimensão } & \multirow{2}{*}{ Atributo } & \multirow{2}{*}{ Indicador } & \multicolumn{5}{|c|}{ Autor (s) - Tabela 2} \\
\hline & & & $\begin{array}{lll}1 & 2 & 3 \\
\end{array}$ & 4 & 5 & 6 & 7 \\
\hline $\begin{array}{l}\text { Serviço ao } \\
\text { cliente }\end{array}$ & Cliente & $\begin{array}{c}\text { Índice de satisfação dos clientes com o serviço prestado } \\
\text { Motivos de reclamação do cliente } \\
\text { Tempo para resolução de problemas }\end{array}$ & $\begin{array}{ll}\sqrt{ } & \sqrt{ } \\
\sqrt{ } & \sqrt{ } \\
\sqrt{ } & \sqrt{ }\end{array}$ & & $\begin{array}{l}\sqrt{ } \\
\sqrt{ } \\
\sqrt{ }\end{array}$ & & $\begin{array}{l}\sqrt{ } \\
\sqrt{ }\end{array}$ \\
\hline Suprimentos & Compras & $\begin{array}{c}\% \text { de ordens de compra perfeitas } \\
\text { Ordens de compra por hora/homem } \\
\text { Tempo de ciclo da ordem de compra }\end{array}$ & & $\begin{array}{l}\sqrt{ } \\
\sqrt{ } \\
\sqrt{ }\end{array}$ & & & \\
\hline $\begin{array}{l}\text { Custos das } \\
\text { operações }\end{array}$ & Custos & $\begin{array}{c}\text { Custos da logística total } \\
\text { Custos de transporte e distribuição } \\
\text { Custos nas operações de centros de distribuição }\end{array}$ & & $\begin{array}{l}\sqrt{ } \\
\sqrt{ } \\
\sqrt{ }\end{array}$ & & & $\begin{array}{l}\sqrt{ } \\
\sqrt{ }\end{array}$ \\
\hline Distribuição & Entrega & $\begin{array}{l}\text { Atendimento a solicitações por condições especiais de entregas } \\
\text { Cooperação do motorista na entrega } \\
\text { Cordialidade, presteza na entrega } \\
\text { Entregas no prazo } \\
\text { Entregas realizadas sem Avarias } \\
\text { Tempo da frota em trânsito } \\
\text { Tempo de descarga na entrega }\end{array}$ & $\begin{array}{lll} & & \\
\sqrt{ } & \sqrt{ } & \sqrt{ } \\
\sqrt{ } & \sqrt{ } & \sqrt{ } \\
\sqrt{ } & \sqrt{ } & \sqrt{ }\end{array}$ & $\begin{array}{l}\sqrt{ } \\
\sqrt{ } \\
\sqrt{ } \\
\sqrt{ }\end{array}$ & $\begin{array}{l}\sqrt{ } \\
\sqrt{ } \\
\sqrt{ } \\
\sqrt{ }\end{array}$ & $\sqrt{ }$ & $\sqrt{ }$ \\
\hline $\mathrm{RH}$ & Pessoas & Segurança e condições de trabalho & & $\sqrt{ }$ & & $\sqrt{ }$ & \\
\hline
\end{tabular}




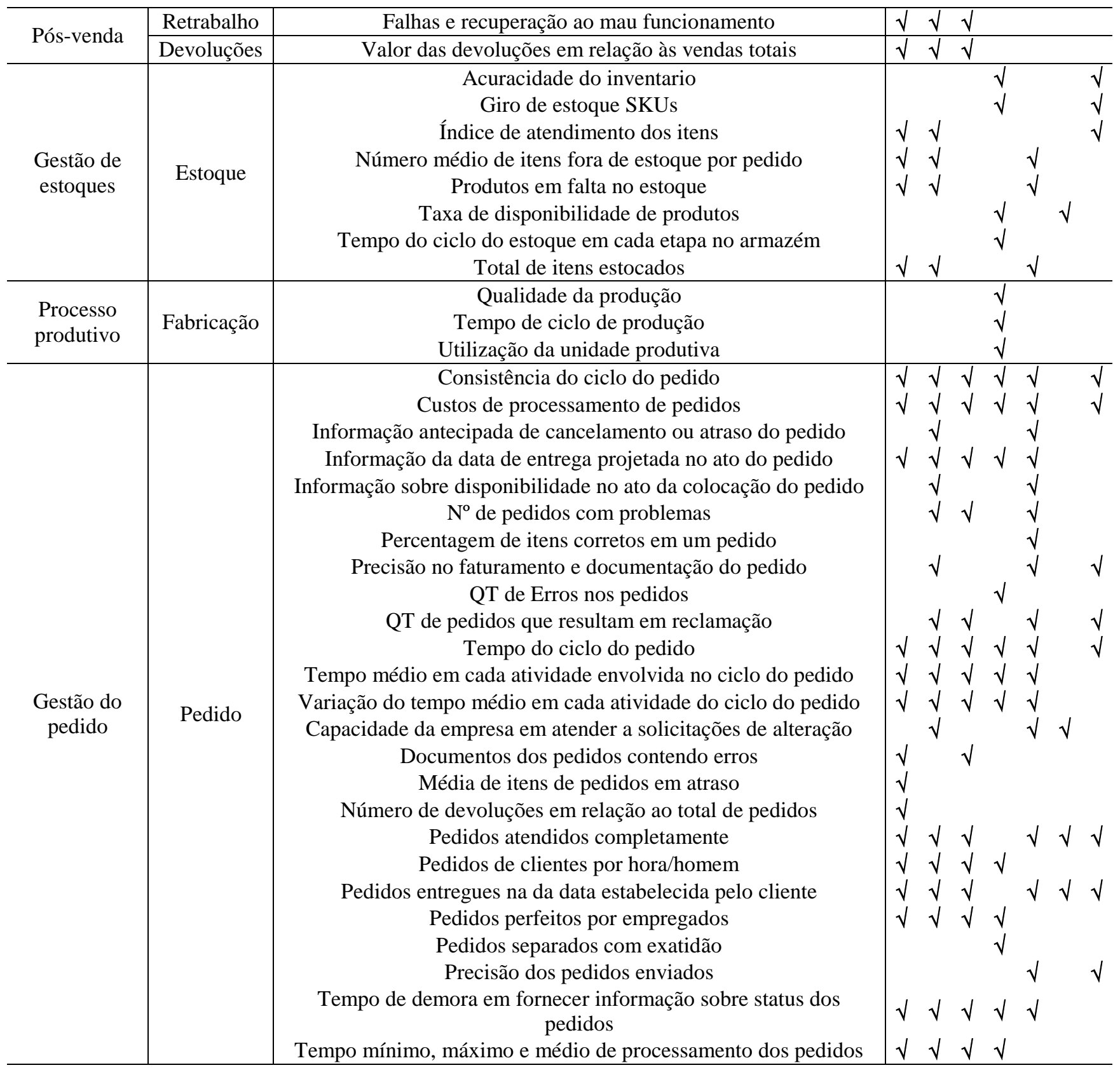

Nesta seção, buscou-se identificar os principais aspectos (dimensão, atributo e indicadores) relacionados ao desempenho da cadeia de suprimentos e também sobre os serviços logísticos. As discussões sobre os resultados da pesquisa são apresentados a seguir.

\section{Análise e discussões dos resultados}

A partir das diversas abordagens analisadas em 15 trabalhos compostos por um total de 29 autores sobre as dimensões e indicadores de desempenho relacionados a cadeia de suprimentos e ao serviço logístico e foram realizadas algumas análises estatísticas simples a fim de extratificar os resultados obtidos para uma maior compreensão.

Inicialmente analisou-se os resultados obtidos a partir da Tabela 2, que aborda as publicações relacionadas as dimensões e indicadores de desempenho voltados a cadeia de 
suprimentos - CS. Em uma primeira análise sobre a quantidade de indicadores abordados pelos autores constatou-se, que; Cravens et al (2000) contemplava 53\% dos indicadores identificados; Gunasekaran et al (2001) 47\%; Bowersox e Closs (2001) 45\%; Beamon (1999) 35\%; Lambert e Pohen (2001) 23\%; Brewer e Speh (2001) 23\%; Supply Chain Council (2006) 18\% e; Stewart (1995) 10\%, conforme a Figura 1. Cabe ressaltar que alguns autores contemplaram em suas abordagens o mesmo indicador, sendo que foi 60 o total de indicadores identificados.

Figura 1- QT de indicadores de desempenho da CS abordados pelos autores

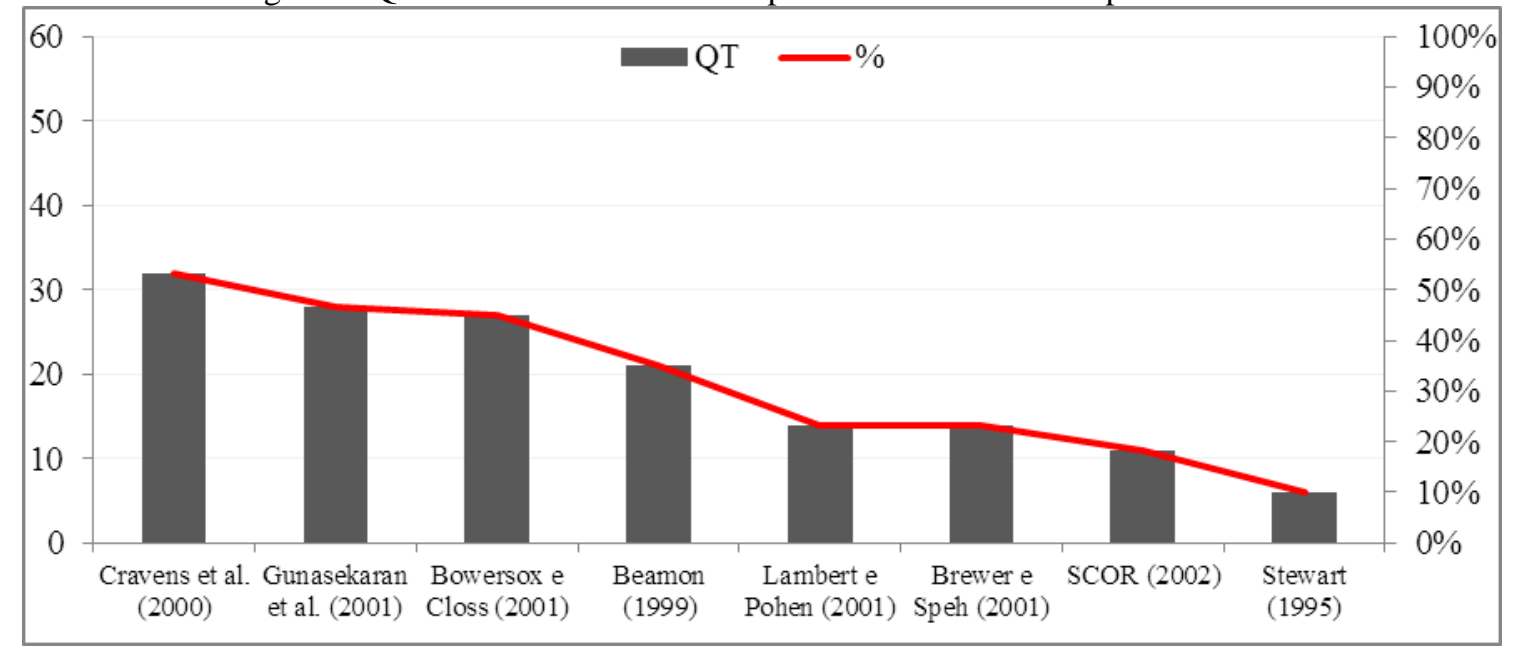

Em análise as dimensões correspondentes aos indicadores de desempenho da cadeia de suprimentos (Figura 2) identificados na pesquisa, verifica-se que Serviço logístico ao Cliente representa 23\%, Distribuição 17\%, Fluxo de caixa 13\%, Gestão de Estoques 12\%, Processo Produtivo $12 \%$, Suprimento $12 \%$, Armazenagem 5\%, Inovação 3\%, Informação $2 \%$ e Recursos Humanos $2 \%$.

Figura 2 - Dimensão dos indicadores de desempenho da cadeia de suprimentos

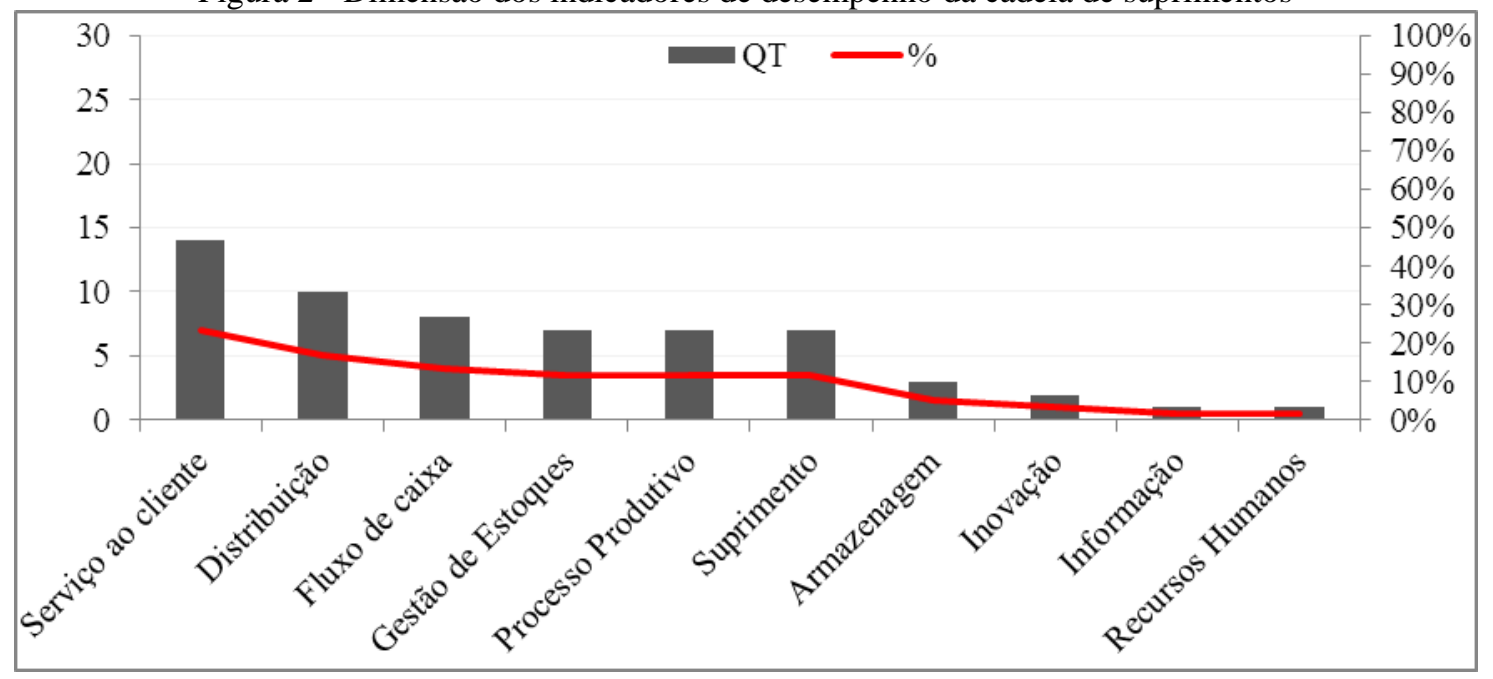

Com relação aos 12 atributos relacionados ao desempenho da cadeia de suprimentos identificados nas publicações, constatou-se que o atributo Cliente corresponde $23 \%$ do total dos 
atributos identificados, Entrega 17\%, Financeiro 13\%, Estoque 12\%, Fabricação 12\%, Fornecedor 7\%, Compras 5\%, Movimentação 3\%, Capacidade de Inovar 3\%, Instalação 2\%, Comunicação 2\% e Aprendizado e Conhecimento 2\% (Figura 3).

Figura 3 - Atributos dos indicadores de desempenho da cadeia de suprimentos

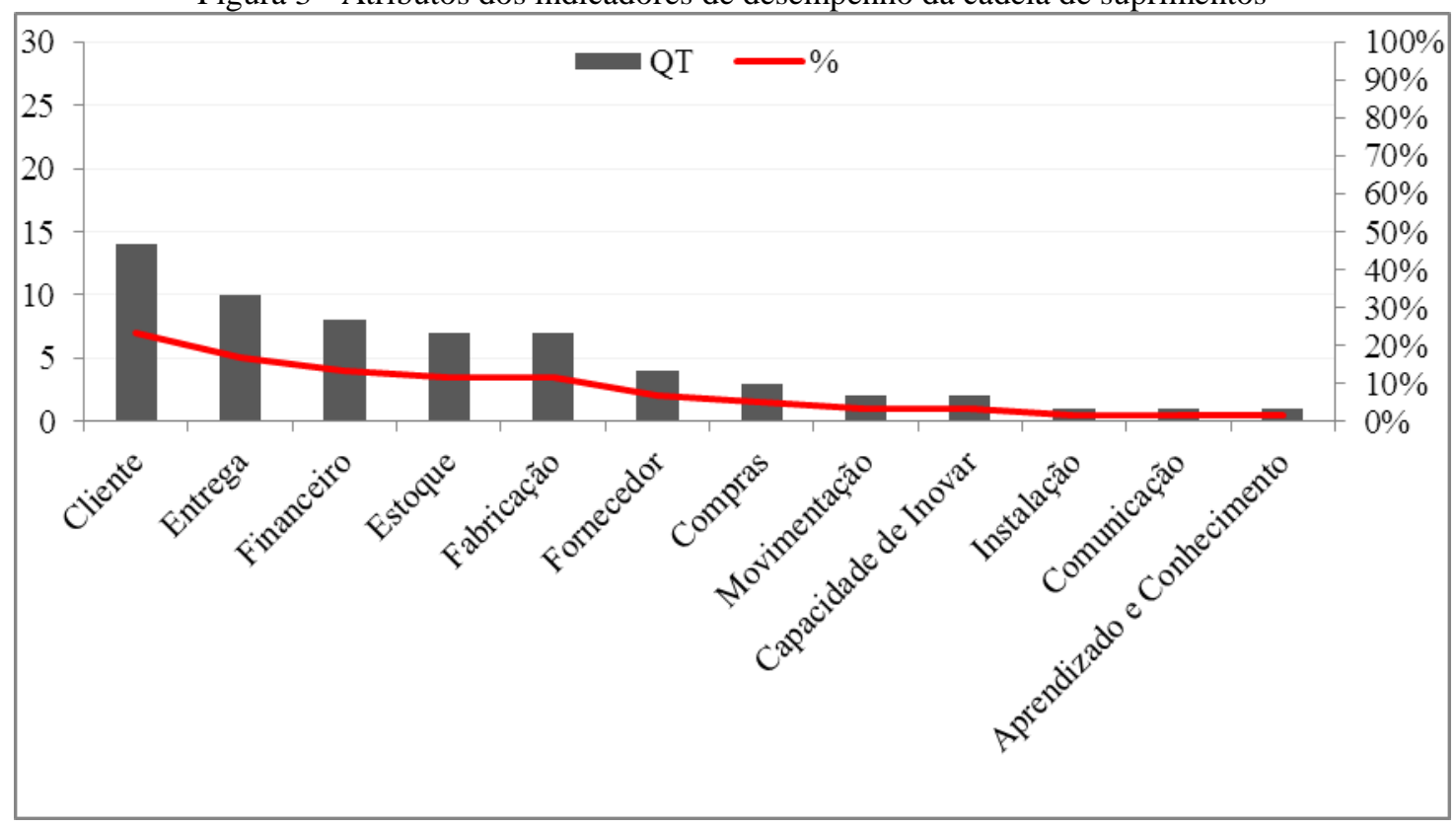

Ao todo foram identificados nas publicações 60 indicadores de desempenho relacionados a cadeia de suprimentos (Tabela 2), dos quais os aspectos voltados ao serviço ao cliente, fluxo de caixa e Financeiro, estoques, processo produtivo e fornecedores estiveram mais evidentes nas dimensões e atributos.

Outra análise realizada pelos autores, diz respeito aos indicadores de desempenho voltados ao serviço logístico. Foram encontrados 54 indicadores, contidos 9 dimensões e 10 atributos e. Analisaram-se as obras de 14 autores (Figura 4)

Figura 4 - QT de indicadores de desempenho do serviço logístico abordado pelos autores

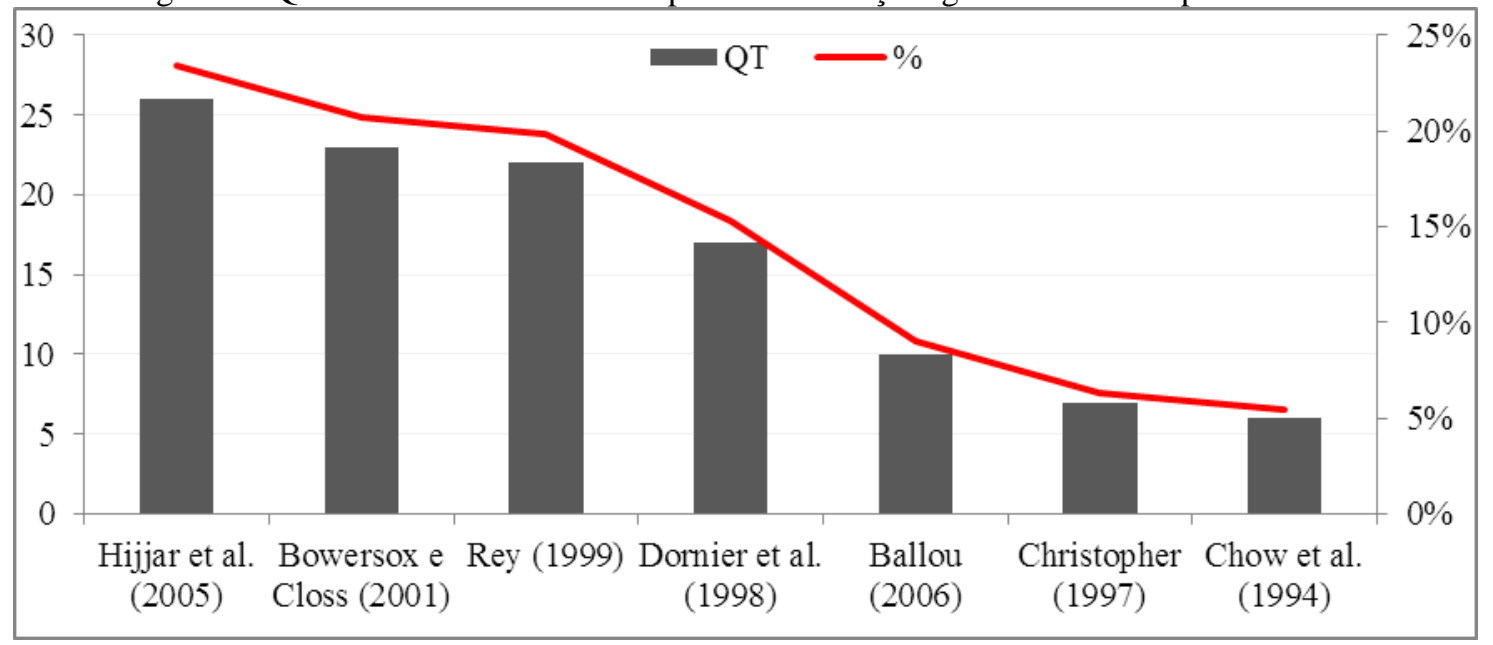


A quantidade de indicadores relacionados ao serviço logístico abordados pelos autores (Figura 4), caracteriza-se por; Hijjar et al (2005) que esta contido em 48\% dos indicadores de desempenho identificados, Bowersox e Closs (2001) 43\%, Rey (1999) 41\%, Dornier et al (1998) 31\%, Ballou (2006) 19\%, Christopher (1997) 13\% e Chow et al (1994) $11 \%$.

Com relação às dimensões do serviço logístico, abordado pelos autores, constatou que a Gestão do Pedido compreende 46,30\%, Gestão de Estoques 14,81\%, Distribuição 12,96\%, Custos 5,56\%, Processo Produtivo 5,56\%, Serviço ao cliente 5,56\%, Pós-venda 3,70\%, Suprimento 3,70\%, Recursos Humanos 1,85\% (Figura 5).

Figura 5 - Dimensão dos indicadores de desempenho do Serviço Logístico

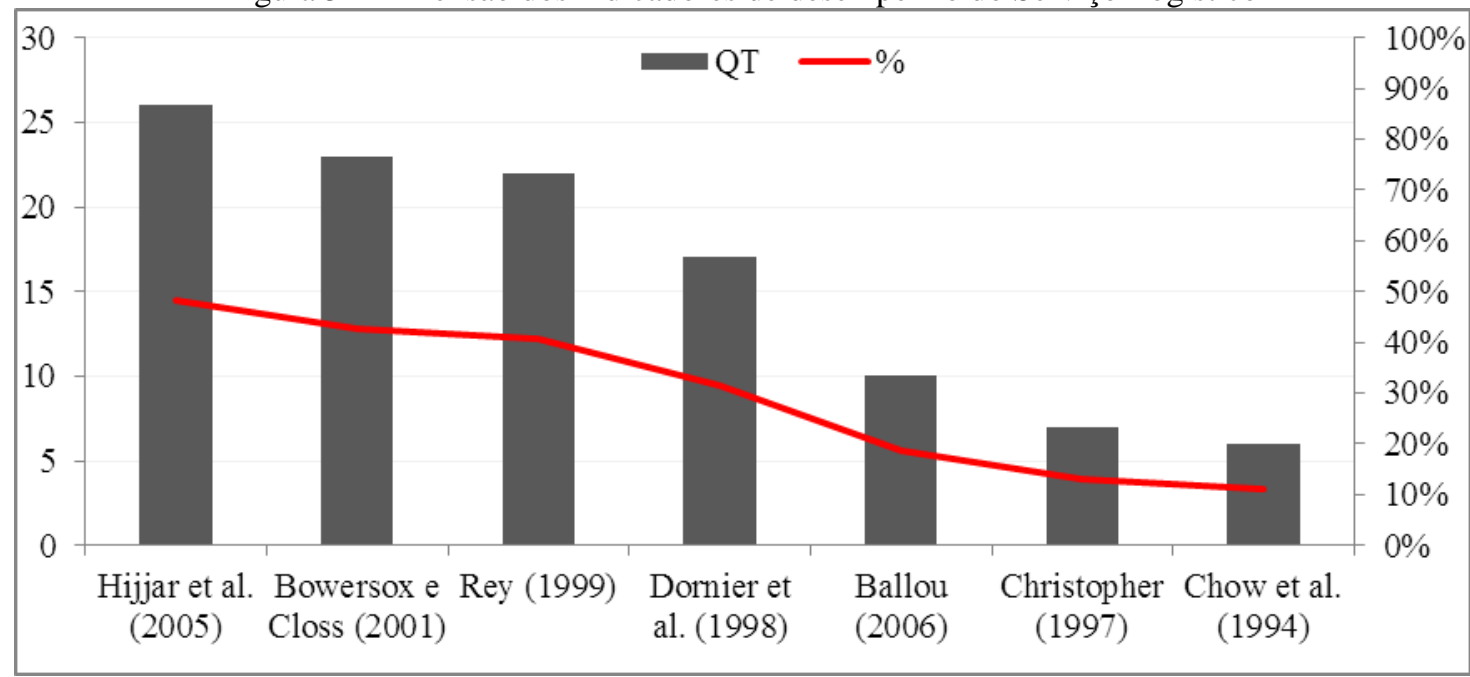

Foram elencados 10 os atributos relacionados aos indicadores de desempenho do serviço logístico contemplados em Pedido correspondendo a 46,30\%, Estoque 14,81\%, Entrega 12,96\%, Custos das Operações 5,56\%, Fabricação 5,56\%, Cliente 5,56\%, Compras 3,70\%, Devoluções $1,85 \%$, Retrabalho $1,85 \%$ e Pessoas $1,85 \%$ (Figura 6).

Figura 6 - Atributos dos indicadores de desempenho do serviço logístico

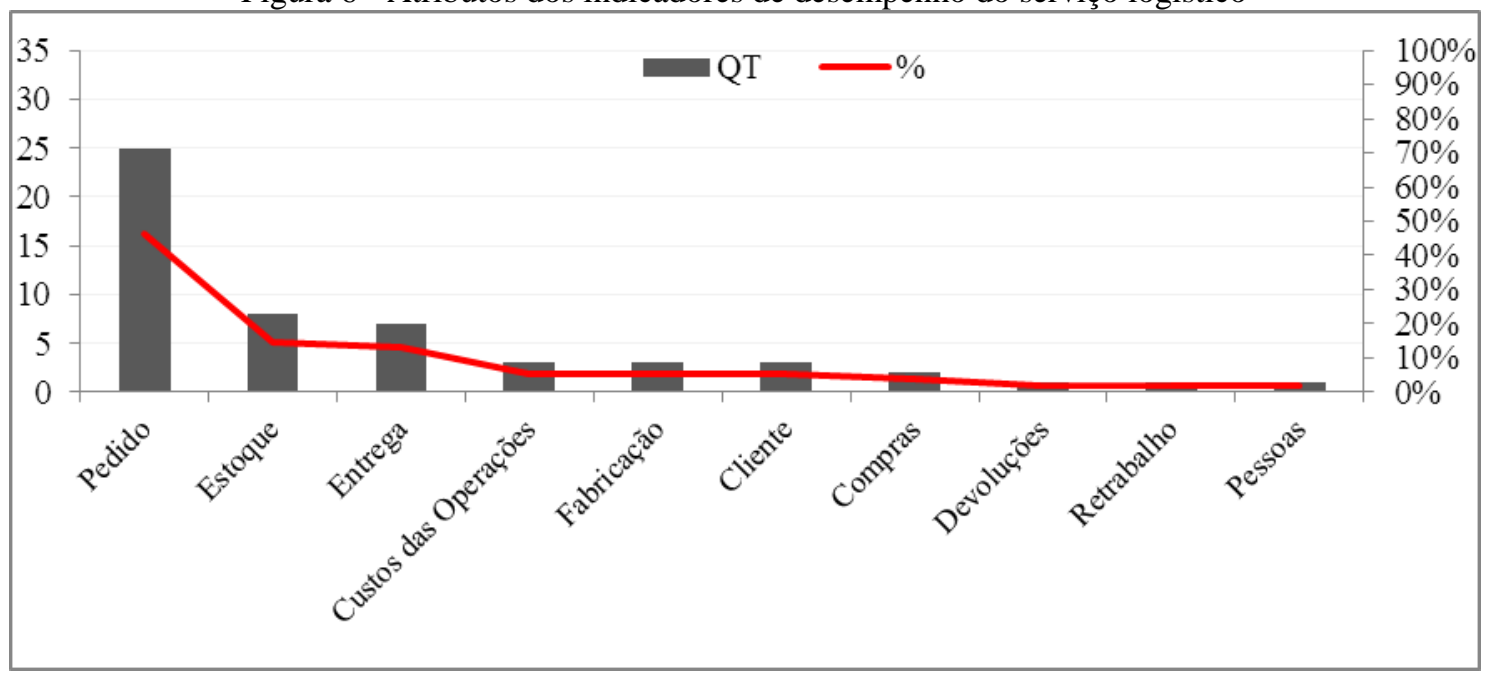


Os indicadores de desempenho voltados ao serviço logístico apresentam uma maior concentração em aspectos voltados aos Pedidos, Estoques e Entregas que estão relacionados diretamente a prestação de serviço junto aos clientes. Isto ficou evidenciado também na abordagem sobre os indicadores de desempenho da cadeia de suprimentos.

\section{Conclusões}

A partir da revisão de literatura desenvolvida ao longo desta pesquisa, foi possível elaborar uma matriz de indicadores de desempenho da gestão da cadeia de suprimentos e também uma matriz voltada aos indicadores relacionados ao serviço logístico, sob forma de corroborar com a governança das plataformas logísticas.

Foram identificados sessenta indicadores de desempenho relacionados à cadeia de suprimentos e cinquenta e quatro indicadores de desempenho voltados ao serviço logístico. Em uma análise conjunta das dimensões (refere-se ao campo e ou ambiente de referência e onde se define e sistematiza dos atributos de desempenho), constata-se que os aspectos voltados a gestão de pedidos apresenta uma maior representatividade (22\%) em relação ao total dos indicadores de desempenho verificados. Outras dimensões foram evidenciadas nas duas matrizes de indicadores (cadeia de suprimentos e serviço logísticos), dentre as quais a Distribuição, Serviço ao Cliente, Processo Produtivo, Suprimentos e Recursos Humanos. Outras dimensões de desempenho também foram apontadas no estudo como Fluxo de Caixa, Armazenagem, Custos, Inovação, Pós-venda e Informação.

As plataformas logísticas podem ser consideradas empreendimentos logísticos complexos, onde diversos atores buscam a racionalização dos seus recursos a fim de obter uma maior eficiência e sinergia tanto em níveis estratégicos, táticos ou mesmo operacionais. O desenvolvimento e a organização das plataformas logísticas são influenciados fortemente pelo grau de relacionamento entre os atores que nela estão inseridos, necessitando assim de uma adequada governança por parte de seus membros. Ainda neste sentido, na medida em que o relacionamento entre as organizações não é um evento isolado entre as próprias organizações com o mesmo poder de influência e decisão sobre assuntos inseridos no objetivo maior da cadeia de suprimentos ocorre uma variação na assimetria do poder, que influencia e é influenciada pelo modelo de governança existente.

A governança é composta por procedimentos associados a tomada de decisões, desempenho e controle das organizações e ambientes, com o fornecimento de estrutura que seja capaz de possibilitar uma direção geral para a organização e também satisfazer as expectativas razoáveis da prestação de contas para os que estão dentro ou são externos a própria organização. A medição de desempenho associada a governança é um tema amplo e vem sendo discutido ao longo dos anos por diversos autores, porém percebe-se na bibliografia publicada que não há uma determinada 
singularidade sobre uma definição clara de quais os indicadores devem ou não ser aplicados a governança, mas sim entende-se através desta pesquisa que a aplicabilidade dos indicadores devem se dar em conformidade ao ambiente analisado.

Os indicadores de desempenho identificados podem ser utilizados para apoiar a governança, possibilitando uma orientação quanto ao caminho e ou direção a ser tomada em razão dos objetivos propostos pelos participantes das plataformas logísticas. O presente trabalho pode representar uma contribuição no sentido de inter-relacionar a temática mensuração de desempenho através da utilização de indicadores desempenho voltada à cadeia de suprimentos e também ao serviço logístico na governança de plataformas logísticas. Contudo, acredita-se que ainda existe muito a ser desenvolvido neste sentido. Como sugestão para futuras pesquisas, propõe-se: i) exploração e identificação de indicadores desempenho voltados aspectos ambientais e ou de responsabilidade social que podem apoiar a governança em plataformas logísticas e, ii) aplicação de ferramentas como analytic hierarchy process - AHP para hierarquizar os indicadores de desempenho identificados.

Outras pesquisas complementares poderiam ainda ser realizadas sobre os indicadores de governança utilizados no âmbito público ou mesmo no corporativo e relacionar os mesmos com a prática da governança em plataformas logísticas. Constata-se também como contribuição deste trabalho, os resultados da pesquisa, os quais poderão ser utilizados como hipóteses para novas observações e aplicações que auxiliem a tornar ainda mais robusto o conhecimento que se tem acerca do desempenho da governança em plataformas logísticas.

\section{Abstract}

The objective of this research was to develop a matrix of performance indicators in the management of supply chain and also a matrix oriented indicators related logistics services that may corroborate the governance of logistics platforms, since these developments show is complex logistical arrangements where various activities are developed with the participation of different actors. The research methodology used is classified as level as exploratory and research strategy adopted was the literature review. The research method used was qualitative. As a result of this research, we identified a set of 19 performance dimensions, composed of 114 performance indicators related to supply chain and logistics service also able to testify to governance, which consists of procedures associated with the decision-making, performance and control organizations. The results of the study can be used for the development of new observations and applications that can make more consistent the knowledge that it has on the performance of governance logistics platforms.

Keywords: logistics performance; governance; logistics platforms.

\section{Referências}

ABRAHAMSSON, M.; ALDIN, N.; STAHRE, F. Logistics platforms for improved strategic flexibility. International Journal of Logistics Research and Applications, v. 6, n. 3, pp. 85-106, 2003. crossref

ALBERS, S. The design of alliance governance systems. Köln: Kölner Wissenschaftsverlag, 2005. 
ALDIN, N.; STAHRE, F. Electronic commerce, marketing channels and logistics platforms - a wholesaler perspective. European Journal of Operational Research, v. 144, n. 2, p. 270-279, 2003. crossref

BALLIS, A.; MAVROTAS, G. Freight village design using the multicriteria method PROMETHEE. Operational Research, v. 7, n. 2, p. 213-231, 2007.

BALLOU, R. H. Gerenciamento da cadeia de suprimentos: planejamento, organização e logística empresarial. Porto Alegre: Bookman, $5^{\mathrm{a}}$ edição, 2006.

BEAMON, B. M. Measuring supply chain performance. International Journal of Operations \& Production Management. v. 19 n. 3, p. 275-292, 1999. crossref

BOWERSOX, D. J.; CLOSS, D. J. Logística empresarial: o processo de integração da cadeia de suprimentos. São Paulo, Atlas, 2001.

BOLUMOLE, Y. Evaluating the Supply Chain Role of Logistics Service Providers. The International Journal of Logistics Management, Cambridge (MA), v. 14, n. 2, p. 93-107, 2003. crossref

BORTOLUZZI, S. C.; ENSSLIN, S. R.; ENSSLIN, L. Avaliação de desempenho dos aspectos tangíveis e intangíveis da área de mercado: estudo de caso em uma média empresa industrial. RBGN Revista Brasileira de Gestão de Negócios, São Paulo, v. 12, n. 37, p. 425-446, 2010.

BREWER, P. C.; SPEH, T. W. Adapting the balanced scorecard to supply chain management. Supply Chain Management Review, v. 5, n. 2, p. 48-56, 2001.

CAMBRA-FIERRO, J.; RUIZ-BENITEZ, R. Advantages of intermodal logistics platforms: insights from a Spanish platform. Supply Chain Management: An International Journal, v. 14, n. 6, p. 418- 421, 2009. crossref

CAMPOLONGO, M.; MORANDI, C.; MARIOTTI, I. La piattaforma logistica di Leixões, Portogallo, e il suo território. Journal of Land Use, Mobility and Environment, v. 3, n. 2, p. 65-72, 2010.

CHOW, G., HEAVER, T. D.; HENRIKSSON, L. E. Logistic perfomance: definition and measurment. International Journal of Physical Distribution \& Logistics Management, v. 24, n. 1, 1994. crossref

CHRISTOPHER, M. Logística e gerenciamento da cadeia de suprimentos: estratégias para a redução de custos e melhoria dos serviços. São Paulo: Pioneira, 1997.

COLLINS, J.; HUSSEY, R. Pesquisa em administração: um guia prático para alunos de graduação e pós-graduação. Porto Alegre: Bookman, $2^{\text {a }}$ edição, 2005.

CRAINIC, T. G., RICCIARDI, N.; STORCHI, G.Advanced freight transportation systems for congested urban areas. Transportation Research Part C. Emerging Technologies, v. 12, n. 2, p. 119-137, 2004. crossref

CRAVENS, K.; PIERCY, N.; CRAVENS, D. Assessing the performance of strategic alliances: matching metrics to strategies. European Management Journal, v. 18, n. 5, p. 529-541, 2000. cross ref

CRESWELL, J. W. Projetos de pesquisa: Métodos qualitativo, quantitativo e misto. Porto Alegre: Artmed, $2^{\mathrm{a}}$ edição, 2007.

COUNCIL OF SUPPLY CHAIN MANAGEMNT AND PROFISSIONALS - CSCMP. Disponível em: <http://cscmp.org/default.asp>. Acesso em: 15 jun. 2013.

DIAS, J. C. Q.; CALADO, J. M. F., OSÓRIO, A. L.; MORGADO, L. F. RFID together with multi-agent systems to control global value chains. Annual Reviews in Control, v. 33, n. 2, p. 185-195, 2009. crossref

DORNIER, P. P.; ERNEST, R., FENDER, M.; KOUVELIS, P. Global operations and logistics: text and cases. New York: John Wiley, 1998.

GAJSEK, B.; LIPICNIK, M.; SIMENC, M. The logistics platform disambiguation. Research in Logistics \& Production, v. 1, n. 1, p. 69-80, 2012.

GRAHAM-MOORE, B.; ROSS, T. L. Gainsharing: plans for improving performance. Washington: BNA, 1993. 
GUNASEKARAN, A., PATEL, C.; TIRTIROGLU, E. Performance measures and metrics in a supply chain management. International Journal of Operations \& Production Management. v. 21, n. 1/2, p. 71-87, 2001. crossref

HESSE, M.; RODRIGUE, J.The transport geography of logistics and freight distribution. Journal of Transport Geography, v. 12, n. 3, p. 171-184, 2004. CRAVENS, K.; PIERCY, N.; CRAVENS, D. Assessing the performance of strategic alliances: matching metrics to strategies. European Management Journal, v. 18, n. 5, p. 529-541, 2000. crossref

HIGGINS, C. D.; FERGUSON, M. R. An Exploration of the Freight Village Concept and its Applicability to Ontario. McMaster Institute of Transportation and Logistics. McMaster University. Hamilton, Ontario. October, p. $195,2011$.

HIJAR, M. F.; GERVÁSIO, M. H.; FIGUEIREDO, K. F. Mensuração de desempenho logístico e o modelo World Class Logistics - Partes 1 e 2. Rio de Janeiro, 2005. Disponível em: <http://www.cel.coppead.ufrj.br/fspublic.htm>. Acesso em: 04 jun. 2013.

KARLSSON, C. Researching Operations Management. New York: Routledge, 2009.

KEARNEY, A. T. Achieving customer satisfaction through logistics excellence. Managing Service Quality, v. 4, n. 2, p. 47-50, 1994. CRAVENS, K.; PIERCY, N.; CRAVENS, D. Assessing the performance of strategic alliances: matching metrics to strategies. European Management Journal, v. 18, n. 5, p. 529-541, 2000. crossref

LAMBERT, D. M.; POHLEN, T. L. Supply chain metrics”. The International Journal of Logistics Management, v. 12, n. 1, p.1-19, 2001. CRAVENS, K.; PIERCY, N.; CRAVENS, D. Assessing the performance of strategic alliances: matching metrics to strategies. European Management Journal, v. 18, n. 5, p. 529-541, 2000. cross ref

LAMBERT, D. M.; COOPER, M. C.; PAGH, J. D. Supply Chain Management: Implementation Issues and Research Opportunities. The International Journal of Logistics Management, v. 9, n. 2, p. 1-19, 1998. CRAVENS, K.; PIERCY, N.; CRAVENS, D. Assessing the performance of strategic alliances: matching metrics to strategies. European Management Journal, v. 18, n. 5, p. 529-541. cross ref

LEE, H. L.; BILLINGTON, C. The evolution of supply chain management models and practice at hewlett-packard. Interfaces, v. 23, n. 5, p. 42-63, 1995. CRAVENS, K.; PIERCY, N.; CRAVENS, D. Assessing the performance of strategic alliances: matching metrics to strategies. European Management Journal, v. 18, n. 5, p. 529-541, 2000. crossref

MARCONI, M. A.; LAKATOS, E. M. Fundamentos de metodologia científica. São Paulo: Atlas, $6^{\text {a }}$ ed., 2009.

MAZZARINO, M. Strategic scenarios of global logistics: what lies ahead for Europe? European Transport Research Review, v. 4, n. 1, p. 1-18, 2012. CRAVENS, K.; PIERCY, N.; CRAVENS, D. Assessing the performance of strategic alliances: matching metrics to strategies. European Management Journal, v. 18, n. 5, p. 529-541, 2000. crossref

MEIDUTE், I. Economical evaluation of logistics centres establishment. Transport, v. 22, n. 2, p. 111-1117, 2007.

MOORI, R. G.; ALMEIDA FILHO, M. A.; MARCONDES, R. C. Desempenho da gestão colaborativa em empresas de alimentos. Base, São Leopoldo, v.4, n.3, p. 201-212, 2007.

PECK, E.; SIX, P.; GLASBY, J.; SKELCHER, C. Governance and Partnerships. Journal of Integrated Care, v. 12, n. 4, p. 3-8, 2004. CRAVENS, K.; PIERCY, N.; CRAVENS, D. Assessing the performance of strategic alliances: matching metrics to strategies. European Management Journal, v. 18, n. 5, p. 529-541, 2000. crossref

PETTIT, S. J.; BERESFORD, A. K. C. Port development: from gateways to logistics hubs. Maritime Policy \& Management, v. 36, n. 3, p. 253-267, 2009. CRAVENS, K.; PIERCY, N.; CRAVENS, D. Assessing the performance of strategic alliances: matching metrics to strategies. European Management Journal, v. 18, n. 5, p. 529-541, 2000. crossref

POIRIER, C.; REITER, S. E. Supply chain optimization: building the strongest total business network". San Francisco: Berrett-Koehler, 1996.

REY, M. F. Indicadores de desempenho logístico. Revista Logmam, v. 30, n. 10, p. 86-90, 1999. 
RIMIENĖ, K.; GRUNDEY, D. Logistics Centre Concept through Evolution and Definition. Engineering Economics, v. 4, n. 1, p. 87-95, 2007.

ROESCH, S. M. A. Projetos de Estágio e de Pesquisa em Administração: guia para estágios, trabalhos de conclusão, dissertações e estudo de caso. São Paulo: Atlas, $3^{\text {a }}$ edição, 2006.

SILVA, R. M.; SENNA, E. T. P.; SENNA, L. A. D.S.; LIMA JÚNIOR, O. F. Governança em plataformas logísticas: uma análise dos elementos e atributos a serem considerados neste tipo de empreendimento logístico. Journal of Transport Literature, v. 7, n. 3, p. 240-269, 2013. CRAVENS, K.; PIERCY, N.; CRAVENS, D. Assessing the performance of strategic alliances: matching metrics to strategies. European Management Journal, v. 18, n. 5, p. 529541,2000 . crossref

STEWART, G. Supply chain performance benchmarking study reveals keys to supply chain excellence. Logistics Information Management, v. 8, n.2, p. 38-44, 1995. CRAVENS, K.; PIERCY, N.; CRAVENS, D. Assessing the performance of strategic alliances: matching metrics to strategies. European Management Journal, v. 18, n. 5, p. 529541. cross ref

SUPPLY CHAIN COUNCIL (SCC). The Supply Chain Operations Reference-model SCOR. Version 8.0. Supply Chain Council Inc, Washington, DC, p. 548, 2006.

SWAMINATHAN, J. M.; SMITH, S. F.; SADEH, N. M. A Multi Agent Framework for Modeling Supply Chain Dynamics. Technical Report, The Robotics Institute, Carnegie Mellon University, 1996.

TRAPPEY, C. V.; LINB, G. Y. P.; TRAPPEY, A. J. C.; LIUD, C. S.; LEED, W. T. Deriving industrial logistics hub reference models for manufacturing based economies. Expert Systems with Applications, v. 38, n. 2, p. 1223-1232, 2011. CRAVENS, K.; PIERCY, N.; CRAVENS, D. Assessing the performance of strategic alliances: matching metrics to strategies. European Management Journal, v. 18, n. 5, p. 529-541, 2000. crossref

TSAMBOULAS, D. A.; KAPROS, S. Freight Village Evaluation Under Uncertainty With Public And Private Financing. Transport Policy, v. 10, n. 2, p. 141-156, 2003. CRAVENS, K.; PIERCY, N.; CRAVENS, D. Assessing the performance of strategic alliances: matching metrics to strategies. European Management Journal, v. 18, n. 5, p. 529541, 2000. crossref

VÁNCZA, J.; EGRI, P.; KARNOK, D. Planning in concert: a logistics platform for production networks. International Journal of Computer Integrated Manufacturing. v. 23, n. 4, p. 297-307, 2010. CRAVENS, K.; PIERCY, N.; CRAVENS, D. Assessing the performance of strategic alliances: matching metrics to strategies. European Management Journal, v. 18, n. 5, p. 529-541, 2010. crossref

WAGNER, T. Regional traffic impacts of logistics-related land use. Transport Policy, v. 17, n. 4, p. 224-229, 2010. CRAVENS, K.; PIERCY, N.; CRAVENS, D. Assessing the performance of strategic alliances: matching metrics to strategies. European Management Journal, v. 18, n. 5, p. 529-541, 2000. crossref

WOOD JR, T.; ZUFFO, P. K. Supply Chain Management. Revista de Administração de Empresas, São Paulo, v. 38, n. 3, p. 55-63, 1998.

\section{Dados dos autores}

Nome completo: Rafael Mozart da Silva

Filiação institucional: Universidade Federal do Rio Grande do Sul

Departamento: LASTRAN - Laboratório de Sistemas de Transportes Escola de Engenharia

Função ou cargo ocupado: Pesquisador

Endereço completo para correspondência: Av. Osvaldo Aranha, 99, $5^{\circ}$ andar, Porto Alegre

Porto Alegre - RS - CEP 90.035-190

Telefones para contato: (051) 33083596 Fax: (051) 33084007

e-mail: rafmozart@ terra.com.br 
Nome completo: Eliana Terezinha Pereira Senna

Filiação institucional: Universidade Estadual de Campinas

Departamento: LALT - Laboratório de Aprendizagem em Logística e Transportes

Função ou cargo ocupado: Professor - Pesquisador

Endereço completo para correspondência: R. Albert Einstein, 951, Sala 02

Cidade Universitária Zeferino Vaz, CEP 13083-852, Barão Geraldo - Campinas - SP

Telefones para contato: Telefax: (019) 3521 - 2346

e-mail: 1sennas@terra.com.br

Submetido em: 20/07/2013

Aceito em: 15/10/2014 